Article

\title{
Valorization of Industrial Lignin as Biobased Carbon Source in Fire Retardant System for Polyamide 11 Blends
}

\author{
Neeraj Mandlekar ${ }^{1,2,3}\left(\mathbb{D}\right.$, Aurélie Cayla ${ }^{2}{ }^{(D}$, François Rault ${ }^{2}$, Stéphane Giraud ${ }^{2, *}$, \\ Fabien Salaün ${ }^{2}(1)$ and Jinping Guan ${ }^{3}$ \\ 1 Politecnico di Torino, Dept. of Applied Science and Technology, 15121 Alessandria, Italy; \\ neeraj-kumar.mandlek@ensait.fr \\ 2 ENSAIT, GEMTEX-Laboratoire de Génie et Matériaux Textiles, F-59000 Lille, France; \\ aurelie.cayla@ensait.fr (A.C.); francois.rault@ensait.fr (F.R.); fabien.salaun@ensait.fr (F.S.) \\ 3 College of Textile and Clothing Engineering, Soochow University, Suzhou 215123, China; \\ guanjinping@suda.edu.cn \\ * Correspondence: stephane.giraud@ensait.fr; Tel.: +33-320-256-464
}

Received: 23 November 2018; Accepted: 16 January 2019; Published: 21 January 2019

\begin{abstract}
In this study, two different types of industrial lignin (i.e., lignosulphonate lignin (LL) and kraft lignin (DL)) were exploited as charring agents with phosphorus-based flame retardants for polyamide 11 (PA11). The effect of lignins on the thermal stability and fire behavior of PA11 combined with phosphinate additives (namely, aluminum phosphinate (AlP) and zinc phosphinate (ZnP)) has been studied by thermogravimetric analysis (TGA), UL 94 vertical flame spread, and cone calorimetry tests. Various blends of flame retarded PA11 were prepared by melt process using a twin-screw extruder. Thermogravimetric analyses showed that the LL containing ternary blends are able to provide higher thermal stability, as well as a developed char residue. The decomposition of the phosphinates led to the formation of phosphate compounds in the condensed phase, which promotes the formation of a stable char. Flammability tests showed that LL/ZnP ternary blends were able to achieve self-extinction and V-1 classification; the other formulations showed a strong melt dripping and higher burning. In addition to this, cone calorimetry results showed that the most enhanced behavior was found when $10 \mathrm{wt} \%$ of LL and AlP were combined, which strongly reduced PHRR $(-74 \%)$ and THR $(-22 \%)$, due to the interaction between LL and AlP, which not only promotes char formation but also confers the stability to char in the condensed phase.
\end{abstract}

Keywords: industrial lignin; Polyamide 11; phosphinate; thermal decomposition; fire retardancy

\section{Introduction}

Over the past two decades, the sustainable development of flame retardant material has become a major topic of concern in industry and academia, due to the toxicity associated with flame retardants and increasing environmental and health safety regulations. This issue has driven the development of flame retardant systems made from renewable resources as possible alternatives to the non-halogenated ones [1]. Nowadays, Polyamide 11 (PA11), a renewable natural high-performance polymer derived from castor seed oil, has gained much attention because of its high mechanical strength and chemical resistance properties [2]. PA11 has been exploited in automotive, aerospace, sports applications, and textile industries [3-5]. However, low flame-retardant properties and extended dripping of PA11 limits its potential applications in high-performance textiles. In order to confer flame retardancy to PA11, intumescent systems based on bioresources are possible substitutes to halogen-free flame retardants. It is believed that the use of materials based on renewable resources can reduce the 
carbon footprint in our environment. Lignin consists of non-toxic polyaromatic polyols, one of the most abundant biopolymers. The majority of industrial lignin is produced annually by the pulp and papermaking industries and the lignocellulosic ethanol industries; approximately 70 million tonnes of lignins are produced per year worldwide [6,7]. However, around $2 \%$ is isolated and comprehensively utilized, and the rest is primarily incinerated for energy recovery. In recent years, the valorization of lignin compounds has attracted growing interest for its potential applications in polymers, due to its competitive price, abundant availability, reactive functional groups, high aromatic carbon content, and tailored capability for structural modification [7-10].

In particular, lignin has been employed to improve the thermal stability of thermoplastic polymers [11-13], exploiting the thermal decomposition of lignin, which takes place over a broad temperature range, since various aromatic functional groups have different thermal stability. More recently, lignin has shown great potential as a biobased carbon source in an intumescent system with traditional flame retardants [14,15] because of its high char yield (about 50-60 wt \%) upon thermal decomposition in inert atmosphere [16]. The char-formation can reduce the heat release rate of the polymeric material during the combustion process. Furthermore, char forming ability of lignin can be exploited for the design of environmentally friendly intumescent systems with phosphorus-based non-halogenated flame retardants. In this context, among various phosphorus flame retardants, metal phosphinates are considered very efficient and have several advantages, being mostly non-hygroscopic, non-toxic, thermally stable $\left(>350^{\circ} \mathrm{C}\right)$, and resistant to hydrolysis. In particular, AlP and ZnP are the most widely used and are found to be very effective flame retardants, especially for polyesters and polyamides [17]. However, they show satisfactory flame-retardant properties only on rather a high loading of about $30 \mathrm{wt} \%$ [18]. Phosphinate loading was conceivably reduced in the presence of synergistic or catalytic compounds. Furthermore, it was found that some nitrogen-containing compounds such as melamine polyphosphate (MPP) and melamine cyanurate (MC) show synergism when combined with phosphinate $[19,20]$. The efficiency was further improved by the addition of zinc borate (ZnB) to AlP and MPP system [21]. The presence of $\mathrm{ZnB}$ led to the formation of stable residue and a dominant barrier effect. In another study, Didane et al. exploited the synergistic effects of Polyhedral Oligomeric Silsesquioxane (POSS) with ZnP in developing flame retardant PET fibres [22]. The addition of synergistic agents enhances the $\mathrm{ZnP}$ efficiency, by reducing its required loading in the polymer matrix.

In order to promote the utilization of biobased lignin as flame retardant additive, our previous study has elucidated the use of lignin (pure grade) as a carbon source with $\mathrm{ZnP}$ [23]. Lignin used in this work was low sulfonate containing ( $4 \%$ sulphur) alkali kraft lignin. Different formulations of pure lignin and $\mathrm{ZnP}$ were prepared and their fire retardancy effect and thermal decomposition behaviour were investigated. It was found that the blends containing $10 \mathrm{wt} \%$ of both additives showed most enhanced flame-retardant properties, due to the formation of a stable char layer with barrier features. Besides, in the present work, we have focused on the use of chemically different industrial lignin (i.e., kraft lignin and lignosulfonate lignin) combined with two different phosphinates, i.e., aluminum phosphinate (AlP) and zinc phosphinate ( $\mathrm{ZnP})$. Lignins exploited in this work were chemically different and less pure than the same used in the previous study. The purpose of this study is to compare the flame-retardant effectiveness of industrial lignin with phosphinate in PA11. To this aim, the different formulations based on phosphinates and lignins were prepared by melt extrusion and thoroughly investigated. The morphology of prepared blends examined by Scanning Electron Microscopy (SEM) analyses. Their effects on the thermal stability and char-forming ability of blends were thoroughly investigated by thermogravimetric (TG) experiments. Fire behaviour of prepared blends was assessed by the vertical flame spread and cone calorimetry tests. Furthermore, the morphology of char residues after cone calorimetry tests was also investigated by SEM. 


\section{Experimental}

\subsection{Materials and Processing}

A biobased Polyamide 11 (PA11), Rilsan ${ }^{\circledR}$ BMNO-TLD; $M_{\mathrm{n}}=17,000 \mathrm{~g} / \mathrm{mol}$, melt flow index $(\mathrm{MFI})=14-20 \mathrm{~g} / 10 \mathrm{~min}$ at $235^{\circ} \mathrm{C}$, supplied from Arkema (Colombes, France), was chosen as the polymer matrix. Flame retardants zinc phosphinate (ZnP), Exolit 950 and aluminum phosphinate (AlP), Exolit 1230, were supplied by Clariant, Muttenz, Switzerland. Two different types of industrial lignins were used as a carbon source, varying in chemical nature: the first one is a lignosulphonate lignin (coded as LL), provided from Domsjö Fabriker AB (Örnsköldsvik Sweden) and the second one is an alkali kraft lignin (coded as DL) obtained from UPM Biochemicals, Helsinki, Finland (European distributor of Domtar BioChoice ${ }^{\circledR}$ lignin). LL contains mainly Na-lignosulfonate (about 70\%) and small amounts of $\mathrm{Mg}$ and Ca lignosulfonates, and some impurities such as ash and carbohydrates (about $20 \%$ ). DL comprises mostly alkali kraft with $90 \%$ purity level. All the materials were dried at $80^{\circ} \mathrm{C}$ for $12 \mathrm{~h}$ before use.

\subsection{Blends Preparation}

The different blend formulations based on PA11, lignins (LL or DL) and phosphinates (ZnP or AlP) were prepared by melt extrusion and labelled as $P A_{X}-L_{Y}-P_{Z}$, where $X$ represents the amount of PA11, L the type of lignin used, $\mathrm{Y}$ the wt \% lignin loading, $\mathrm{P}$ the type of phosphinate, and $\mathrm{Z}$ the wt \% phosphinate content. A total of $20 \mathrm{wt} \%$ loading was used in blend formulation; phosphinate, being the major component, was varied from 10 to $15 \mathrm{wt} \%$ and lignin from 5 to $10 \mathrm{wt} \%$ (Table 1). Blends were prepared using a co-rotating intermeshing twin-screw extruder (Thermo Haake, screw diameter $=16 \mathrm{~mm}, \mathrm{~L} / \mathrm{D}=25$ ); the temperatures of the five heating zones ranged from 170 to $220^{\circ} \mathrm{C}$, and the rotation speed was set at $100 \mathrm{rpm}$. In all cases, the extruded rods were pelletized for thermal analysis. $3 \mathrm{~mm}$ thick plates were manufactured by compression molding using a Collins Teach Line 200 hydraulic press, operating at 60 bars and $220^{\circ} \mathrm{C}$ for $3 \mathrm{~min}$. Specimens in accordance with cone calorimeter $\left(100 \times 100 \mathrm{~mm}^{2}\right)$ and UL-94 flammability $\left(125 \times 12.5 \mathrm{~mm}^{2}\right)$ tests were prepared and used.

Table 1. Polyamide 11 (PA11) blend formulations with different lignin and phosphinate.

\begin{tabular}{cccc}
\hline Sample & Polyamide $\mathbf{1 1}(\mathbf{w t} \mathbf{\%})$ & Lignin $\left(\mathbf{L}^{\mathbf{1}}\right.$ in wt $\left.\%\right)$ & Phosphinate $^{\left(\mathbf{P}^{\mathbf{1}} \text { in wt } \mathbf{~}\right)}$ \\
\hline PA11 & 100 & - & - \\
$\mathrm{PA}_{80}-\mathrm{L}_{20}$ & 80 & 20 & - \\
$\mathrm{PA}_{80}-\mathrm{P}_{20}$ & 80 & - & 20 \\
$\mathrm{PA}_{80}-\mathrm{L}_{5}-\mathrm{P}_{15}$ & 80 & 5 & 15 \\
$\mathrm{PA}_{80}-\mathrm{L}_{7}-\mathrm{P}_{13}$ & 80 & 7 & 13 \\
$\mathrm{PA}_{80}-\mathrm{L}_{10}-\mathrm{P}_{10}$ & 80 & 10 & 10 \\
\hline
\end{tabular}

${ }^{1}$ Samples name are coded as $\mathrm{PA}_{X}-\mathrm{L}_{Y}-\mathrm{P}_{Z}$, where L is the kind of lignin, i.e., LL (lignosulphonate lignin from Domsjö Fabriker AB) or DL (kraft lignin from UPM Biochemicals), P is the type of phosphinate, i.e., ZnP (zinc phosphinate, OP950) or AlP (aluminium phosphinate, OP1230)

\subsection{Morphology}

Morphology and distribution of the fillers in polymer matrix were assessed by SEM; analyses were carried out using a LEO-1450VP apparatus (Carl Zeiss, Oberkochen, Germany), equipped with a X-ray probe (INCAEnergy Oxford Instruments, $\mathrm{Cu} \mathrm{K} \alpha$ X-ray source, $\mathrm{k}=1.540562 \AA$, Abingdon-on-Thames, UK) under the voltage of $20 \mathrm{kV}$. Energy dispersive X-rays (EDX) elemental mapping was also used for assessing the dispersion of phosphinate and lignin in PA11 matrix. Pellets of different blends were fractured in liquid nitrogen and then coated with a thin conductive gold layer.

\subsection{Thermal Decomposition}

Thermogravimetric (TG) analyses were carried out with a TA instruments thermal analyzer Q500 (New Castle, DE, USA), either under air or nitrogen atmosphere at a purge rate of $60 \mathrm{~mL} / \mathrm{min}$, 
with a heating rate of $10{ }^{\circ} \mathrm{C} / \mathrm{min}$ from 50 to $800{ }^{\circ} \mathrm{C}$, using alumina pans and sample weight of $10 \pm 0.2 \mathrm{mg}$. TG curves were recorded from experiments and dTG (derivative) curves were obtained from TA universal data analysis software for all the samples. The decomposition parameters, such as the temperature at $5 \%$ weight loss $\left(T_{5 \%}\right)$, and residue at $700{ }^{\circ} \mathrm{C}$, were obtained from TG curve. Furthermore, the maximum mass loss rate (MMLR) and the corresponding temperature $\left(T_{\max }\right)$ were obtained from dTG curves. During TG analyses in air, the main decomposition step $\left(T_{\max 1}\right)$ and the second thermo-oxidative degradation step $\left(T_{\max 2}\right)$ were evaluated.

The weight difference curves were plotted in order to determine the potential increase or decrease in the thermal stability of the blends. The weight difference curves were computed for the loaded samples, and correspond to the weight difference between the experimental and theoretical TG curves:

$$
\Delta(M(T))=M_{\exp }(T)-M_{\text {theo }}(T)
$$

Where, $\Delta(M(T))$ is a residual weight difference, $M_{\exp }(T)$ is the experimental residual weight of blends (variation with temperature $T$ ), $M_{\text {theo }}(T)$ is the theoretical residual weight of the same composition computed by a linear combination between the experimental weights of PA11 and additives. The curves show the subsequent interaction between additives and polyamide matrix by the observation of an increase or decrease of the thermal stability.

\subsection{Fire Behavior}

The flammability was evaluated on sample sheets $\left(125 \times 12.5 \times 3 \mathrm{~mm}^{3}\right)$ by vertical flame spread tests according to IEC 60695-11-10 [24], also known as UL 94 burning flame test, and used for plastic materials. This test is aimed at assessing the material capability to extinguish a flame. Materials were classified on the basis of burning rate, time to flame extinction, and dripping during burning.

Cone calorimeter tests were carried out at a heat flux of $35 \mathrm{~kW} \mathrm{~m}^{-2}$ to assess the forced combustion behavior of sheets $\left(100 \times 100 \times 3 \mathrm{~mm}^{3}\right)$ in accordance with ISO 5660 standard [25]. The distance between the sample and the heating cone was increased to $60 \mathrm{~mm}$ due to the material swelling. It was assumed that this swelling behavior was attributed to stress release under heat flux, which was formed during cone plate manufacturing. Before performing the tests, all specimens were conditioned at $23^{\circ} \mathrm{C}$ and $50 \% \mathrm{RH}$ for $72 \mathrm{~h}$. Three tests were carried out on each formulation, and the results averaged. According to this analytical method, critical parameters were evaluated, namely: time to ignition (TTI), heat release rate (HRR), total heat release (THR); furthermore, parameters related to smoke release such as total smoke release (TSR), $\mathrm{CO}_{2}, \mathrm{CO}$, and $\mathrm{CO}_{2} / \mathrm{CO}$ yield were also evaluated.

\section{Results and Discussion}

\subsection{Morphology of Blends}

The dispersion of the lignin and phosphinates in the PA11 matrix was assessed by SEM. The final properties of the blends, such as the flame-retardant performance, depend on the quality of dispersion of the fillers in the polymer matrix [26]. Figure 1a-i shows fractured cross-section images of PA11 and its binary and ternary blends with lignin and phosphinate. It was experienced that during thermo-mechanical compounding the additives size in the polymer matrix is reduced from their original size (Figure S1, Supporting information). From Figure 1b,c, the distribution of LL and DL can be observed for $\mathrm{PA}_{80}-\mathrm{LL}_{20}$ and $\mathrm{PA}_{80}-\mathrm{DL}_{20}$ binary blends, showing no aggregates, and particles are distributed in the entire surface. However, larger size (less than $10 \mu \mathrm{m}$ ) immiscible lignin particles can be observed due to a higher concentration of lignin in binary blends. In addition to this, $\mathrm{PA}_{80}-\mathrm{ZnP}_{20}$ binary blend exhibit distribution of $\mathrm{ZnP}$ particles in the polymer matrix. The larger size $\mathrm{ZnP}$ particles are observed to be due to broad size distribution in pristine $\mathrm{ZnP}$. It is observed that blends containing $\mathrm{ZnP}$ show circular cavity, which can be ascribed to a fusible characteristic of $\mathrm{ZnP}$ [27]. However, a micrograph of the $\mathrm{PA}_{80}-\mathrm{AlP}_{20}$ binary blend (Figure 1d) shows homogenous distribution and good compatibility between AlP and polymer phase. 

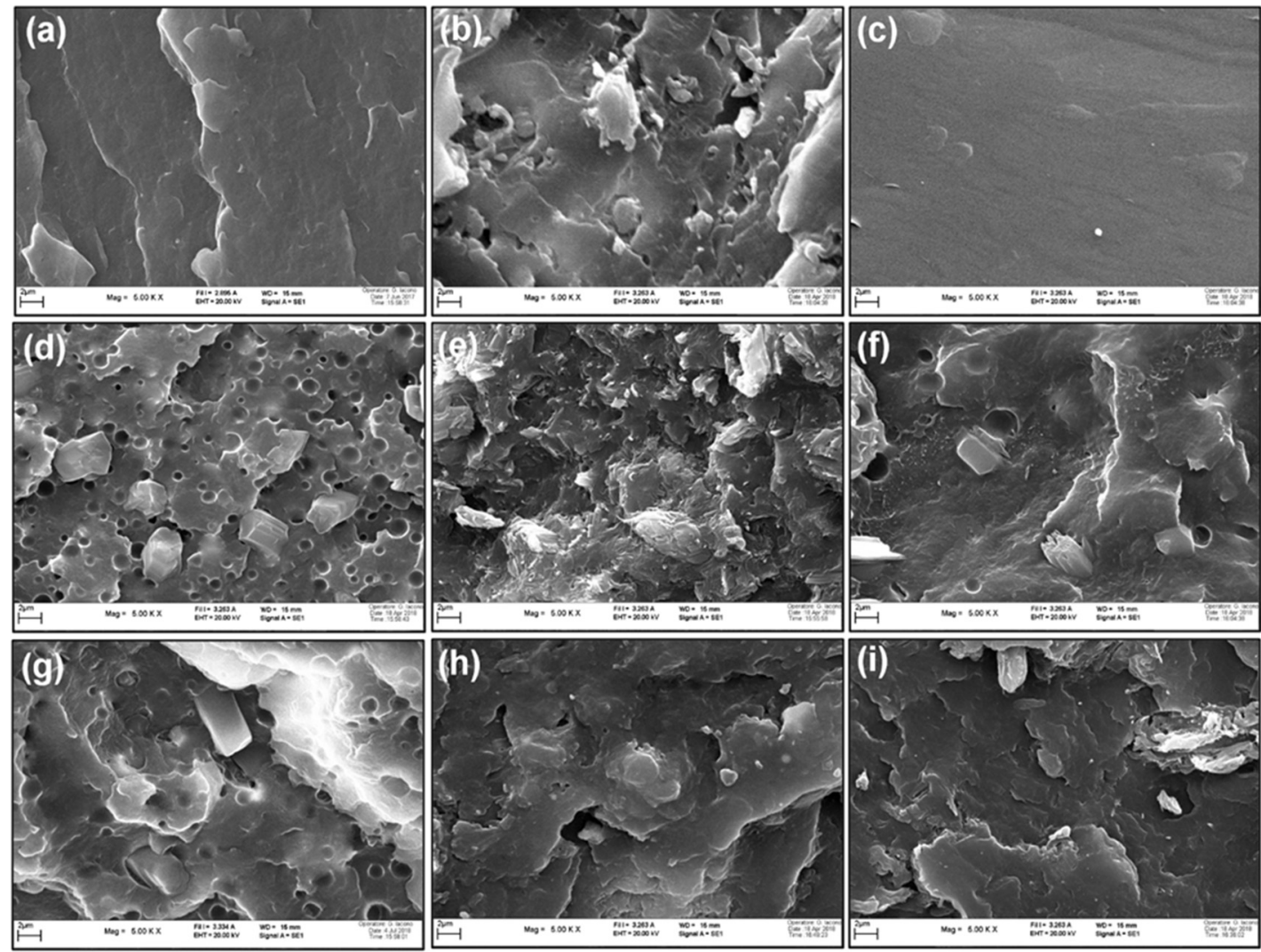

Figure 1. Scanning Electron Microscopy (SEM) micrograph of polyamide 11 (PA11) and its binary and ternary blends. (a) PA11; (b) $\mathrm{PA}_{80}-\mathrm{LL}_{20}$; (c) $\mathrm{PA}_{80}-\mathrm{DL}_{20}$; (d) $\mathrm{PA}_{80}-\mathrm{ZnP}_{20}$; (e) $\mathrm{PA}_{80}-\mathrm{AlP}_{20}$; (f) $\mathrm{PA}_{80}-\mathrm{LL}_{10}-\mathrm{ZnP}_{10}$; (g) $\mathrm{PA}_{80}-\mathrm{DL}_{10}-\mathrm{ZnP}_{10} ;$ (h) $\mathrm{PA}_{80}-\mathrm{LL}_{10}-\mathrm{AlP}_{10} ;$ (i) $\mathrm{PA}_{80}-\mathrm{DL}_{10}-\mathrm{AlP}_{10}$ at $5000 \times$ magnification.

In order to further assess the dispersion, EDX maps of Carbon and Phosphorus and EDX spectra of ternary blends containing $10 \mathrm{wt} \%$ loading of both the fillers are also presented in Figure 2a-e. In fact, it is commonly accepted that EDX mapping spectra can give the qualitative evidence of dispersion and distribution level of the elements [28]. As far as lignin distribution is concerned, it was observed during the blend preparation process that lignin particles are broken down and mixed well with PA11 matrix; furthermore, SEM micrographs show a homogeneous distribution of lignin particles in the polymer matrix, as no phase separation or agglomeration is observed; this indicates reasonable compatibility between lignin and PA11 [16]. In addition to this, Figure 2b,c shows the morphology and distribution of AlP in combination with LL and DL. AlP was found in the entire surface, though small agglomerations $(<10 \mu \mathrm{m})$ are randomly observed. EDX mapping of phosphorus confirms the uniform distribution of the phosphinate in the blends. Carbon (C), Oxygen (O), Aluminium (Al) and Phosphorus (P) elements were mainly detected and confirmed the presence of AlP and lignin within the polymer matrix. In addition to this, the ternary blends of $\mathrm{ZnP}$ with DL/LL (Figure 2d,e) display a larger particle size of $\mathrm{ZnP}$ embedded in the matrix; this morphology was observed due to the broad range of size distribution in the pristine $\mathrm{ZnP}$ (Figure S1, Supporting information). EDX elemental mapping and corresponding spectra further confirm the identification of $\mathrm{C}, \mathrm{O}, \mathrm{Zn}$, and $\mathrm{P}$ in the entire surface. However, apart from larger size, $\mathrm{ZnP}$ particles are uniformly dispersed in the entire surface, without agglomeration phenomena. 

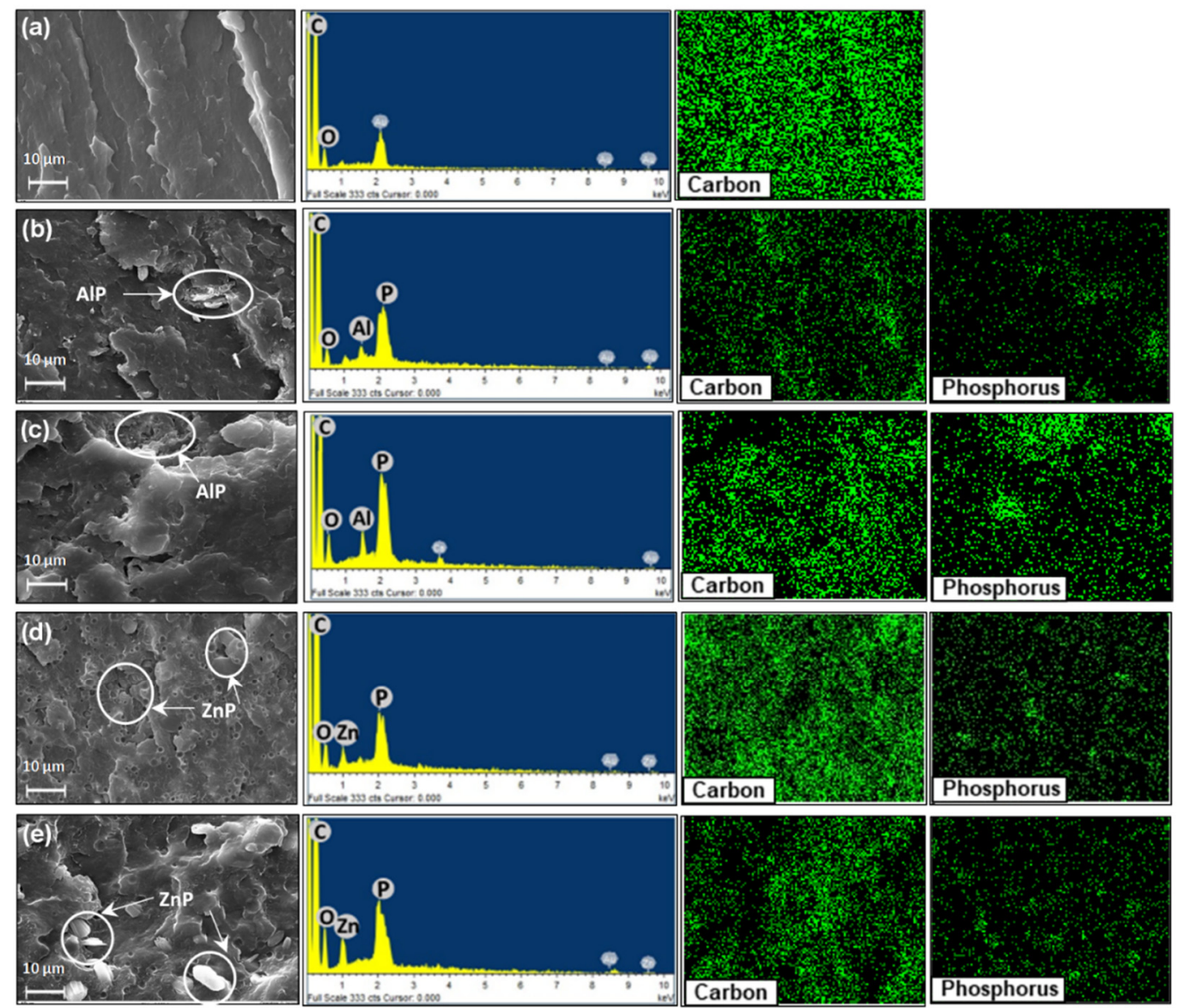

Figure 2. Scanning Electron Microscopy (SEM) micrographs of unfilled polyamide 11 (PA11) and the ternary blends. (a) PA11; (b) $\mathrm{PA}_{80}-\mathrm{LL}_{10}-\mathrm{AlP}_{10}$; (c) $\mathrm{PA}_{80}-\mathrm{DL}_{10}-\mathrm{AlP}_{10}$; (d) $\mathrm{PA}_{80}-\mathrm{DL}_{10}-\mathrm{ZnP}_{10}$ and (e) $\mathrm{PA}_{80}-\mathrm{LL}_{10}-\mathrm{ZnP}_{10}$ at $2500 \times$ magnification and corresponding energy dispersive $\mathrm{X}$-rays (EDX) spectra and elemental maps.

\subsection{Decomposition Behavior}

The thermal and thermo-oxidative stability of PA11 and blends was assessed by TG analyses in $\mathrm{N}_{2}$ and air atmosphere, respectively. Thermogravimetric data are collected in Table 2. However, TGA curves of neat material are presented in Figure S2 (Supporting information). The thermal stability and degradation profile of the binary and the ternary blends are shown in Figures 3 and 4 . In $\mathrm{N}_{2}$ atmosphere, unfilled PA11 starts decomposing at $396^{\circ} \mathrm{C}\left(T_{5 \%}\right)$ and shows single decomposition step with a maximum mass loss at $430^{\circ} \mathrm{C}\left(T_{\max }\right)$ without leaving any residue at the end of the test: a similar behavior was reported in previous studies [16,23]. However, in air, PA11 decomposes in two steps; the first step is at around $454{ }^{\circ} \mathrm{C}\left(T_{\max 1}\right)$, giving rise to the formation of volatile products. The second step, at around $574{ }^{\circ} \mathrm{C}\left(T_{\max 2}\right)$, can be attributed to the further oxidation of hydrocarbon species with the formation of $\mathrm{CO}$ and $\mathrm{CO}_{2}$, leading to a consistent weight loss until $800{ }^{\circ} \mathrm{C}$. 

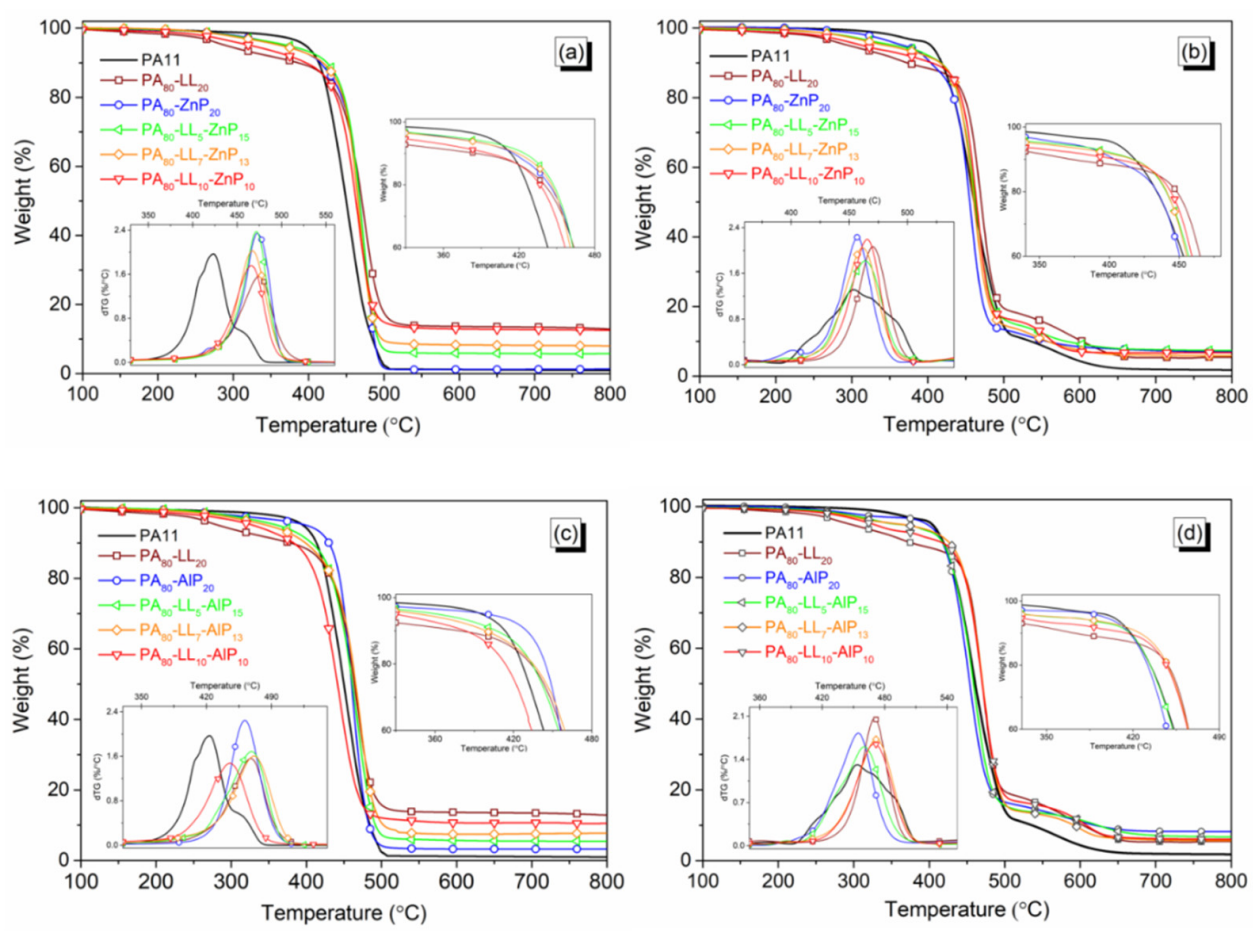

Figure 3. Thermogravimetric (TG) curves of polyamide 11 (PA11) blends of lignosulphonate lignin (LL) in combination with zinc phosphinate $(\mathrm{ZnP})$ and aluminum phosphinate (AlP) in $\mathrm{N}_{2}((\mathbf{a})$ and (c)) and air atmosphere $((\mathbf{b})$ and $(\mathbf{d}))$.

TGA data of the binary blends are summarized in Table S1 (Supporting information). The presence of LL or DL in binary blends initiate the degradation (i.e., lowering $5 \mathrm{wt} \%$ loss) at 285 and $341^{\circ} \mathrm{C}$, respectively. In nitrogen, LL shows a slower decomposition rate compared to DL, leading to the thermal stability shifts to a higher temperature; consequently, its blend generates a higher amount of char residue $\left(13.5 \mathrm{wt} \%\right.$ at $\left.700{ }^{\circ} \mathrm{C}\right)$ as compared to the theoretical one (12.5 wt \%). Furthermore, in inert atmosphere, the thermal stability of binary blends of $\mathrm{ZnP}$ and AlP increases, and a single decomposition step occurs within 460 to $470{ }^{\circ} \mathrm{C}$. In addition, a slightly higher residue for $\mathrm{PA}_{80}-\mathrm{AlP}_{20}$ blend reveals that the interaction between AlP and polymer matrix, resulting in a thermally stable residue compared to the residue from the $\mathrm{PA}_{80}-\mathrm{ZnP}_{20}$ blend [29].

In air, the blends containing DL generate a lower amount of char residue because of the destabilization of the resulting char. Conversely, blends containing a higher amount of $\mathrm{ZnP}$ or AlP generate a higher residue, due to the formation of the phosphate compounds in the condensed phase, as it will be later demonstrated.

When phosphinates (ZnP/AlP) and lignins (LL/DL) were combined with PA11, the decomposition behaviour changed (Figures 3 and 4). In all ternary blends, the presence of any lignin reduces the initial decomposition temperature $\left(T_{5 \%}\right)$; at the same time, $T_{\max }$ increases. This behaviour is ascribed to the lignin degradation, which starts at a lower temperature and continues at a very slow rate; at the end, a noticeable amount of char residue is collected. It is noteworthy that, increasing the LL loading in PA-LL-ZnP blends strongly influences the $T_{5 \%}$ and MMLR; as a consequence, the recorded experimental char residue is higher with respect to the theoretical one, thus indicating the positive interaction within the additives. These blends generate slightly higher residue as compared to the lignin and $\mathrm{ZnP}$ combination used in our previous study [23]. It is assumed that, during the decomposition of $\mathrm{LL}$, the sulfonate compounds release $\mathrm{SO}_{2}$ and transform it into thermally stable $\mathrm{Na}_{2} \mathrm{SO}_{4}$, giving rise to a stable char [30]. Unlike PA-LL-ZnP blends, increasing DL content in its ternary blends slightly influence the $T_{5 \%}$ and the thermal stability of the ternary blends; in particular, a higher mass loss and a lower char residue at the end of the experiment are observed. The lower production of the char residue from DL containing blends with respect to LL counterpart can be attributed to 
their different chemical structure; in particular, DL contains a higher number of less thermally stable methoxy groups that give rise to the formation of more volatile products during decomposition [31]. As far as the thermo-oxidative stability is concerned, the ternary bends show a similar trend, with two decomposition steps: the first one is attributed to the main degradation occurring within 450 to $470{ }^{\circ} \mathrm{C}\left(T_{\max 1}\right)$, giving rise to the formation of volatile products such as phosphinate compounds and phosphinic acid; the second step, occurring at around 550 to $610{ }^{\circ} \mathrm{C}\left(T_{\max 2}\right)$ is attributed to the formation of thermally stable phosphate compounds in the condensed phase [32,33]. It was noticed that ternary blends containing AlP show a second decomposition step between 600 and $610{ }^{\circ} \mathrm{C}\left(T_{\max 2}\right)$ compared to $\mathrm{ZnP}$ containing ternary blends, which give $T_{\max 2}$ at lower temperatures (i.e., within 550 and $580^{\circ} \mathrm{C}$ ). This finding confirms that the phosphate compound formation from AlP is more favored than that from $\mathrm{ZnP}$. Furthermore, the residue obtained in oxidative condition was lower compared to the theoretical one; this finding can be ascribed to the presence of an impurity in the lignin due to their industrial nature, which catalyzes a further oxidation with the formation of $\mathrm{CO}$ and $\mathrm{CO}_{2}$.
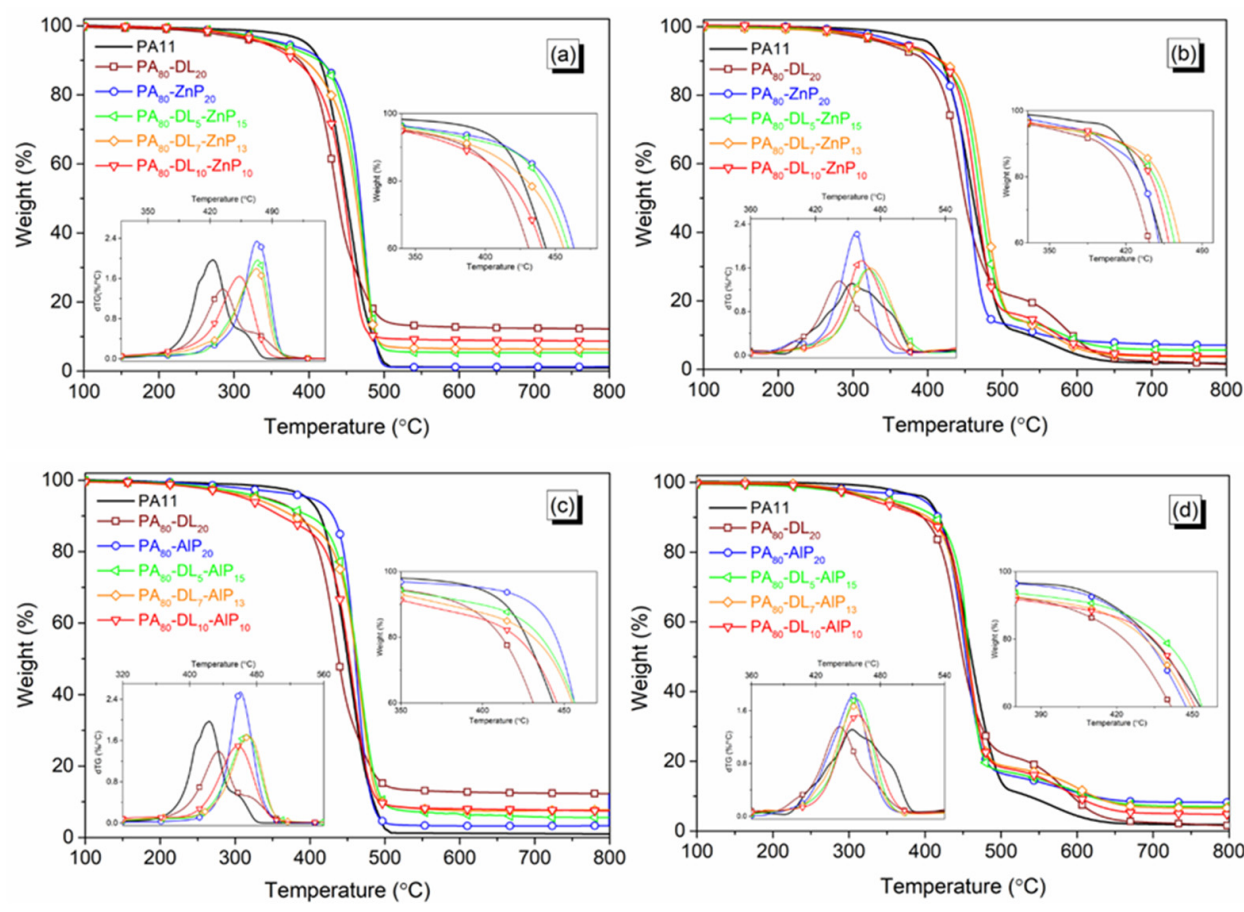

Figure 4. Thermogravimetric (TG) curves of polyamide 11 (PA11) blends of kraft lignin (DL) in combination with zinc phosphinate $(\mathrm{ZnP})$ and aluminum phosphinate (AlP) in $\mathrm{N}_{2}((\mathbf{a})$ and (c)) and air atmosphere ((b) and (d)).

The thermo-oxidative behavior of the prepared blends was assessed through weight loss difference curves $\Delta \mathrm{M}(\%)$. Those collected in Figure $5 \mathrm{a}, \mathrm{b}$, show the interactions among lignin, phosphinates, and PA11. Figure 5a shows stabilization and destabilization region in ternary blends of LL with AlP and $\mathrm{ZnP}$. The blends show slightly destabilization ( $\triangle \mathrm{M}$ is below $-2 \%$ ) region between 270 and $380{ }^{\circ} \mathrm{C}$ and then stabilization from 380 to $460{ }^{\circ} \mathrm{C}$; afterwards, the destabilization region continues until $800{ }^{\circ} \mathrm{C}$. In addition, an increase of $\Delta \mathrm{M}$ and thermal stability was observed with increasing LL loading in blends, hence confirming the positive interaction of LL with fire retardant additives. For example, $\mathrm{PA}_{80}-\mathrm{LL}_{10}-\mathrm{AlP}_{10}$ blend shows stabilization from 415 to $482{ }^{\circ} \mathrm{C}$, and then destabilization of transient char continues up to $800^{\circ} \mathrm{C}$. On the other hand, the presence of DL with AlP and $\mathrm{ZnP}$ decreases the thermal stability, as assessed by the destabilization at a lower temperature (within 270 and $400{ }^{\circ} \mathrm{C}$, Figure $5 b)$. Further, PA-DL-AlP blends show small stabilization region $(\Delta \mathrm{M}$ is below $5 \%$ ) between 400 and $450{ }^{\circ} \mathrm{C}$ and large destabilization $\left(\Delta \mathrm{M}\right.$ is below $-16 \%$ ) between 450 and $520^{\circ} \mathrm{C}$ due to the evolution of more volatile compounds. Finally, stabilization of transient char continues until $800{ }^{\circ} \mathrm{C}$ due to the 
formation of a stable phosphate layer in the solid phase. The replacement of AlP with ZnP widens the stabilization region $(\Delta \mathrm{M}$ is about $12 \%)$ between 400 and $500^{\circ} \mathrm{C}$; then, the destabilization $(\Delta \mathrm{M}$ is less than $-5 \%$ ) of transient char continues until $800{ }^{\circ} \mathrm{C}$. Interestingly, increasing the DL content has no positive influence on mass difference and stabilization region, thus indicating a poor interaction of DL with fire retardant additive in PA11.
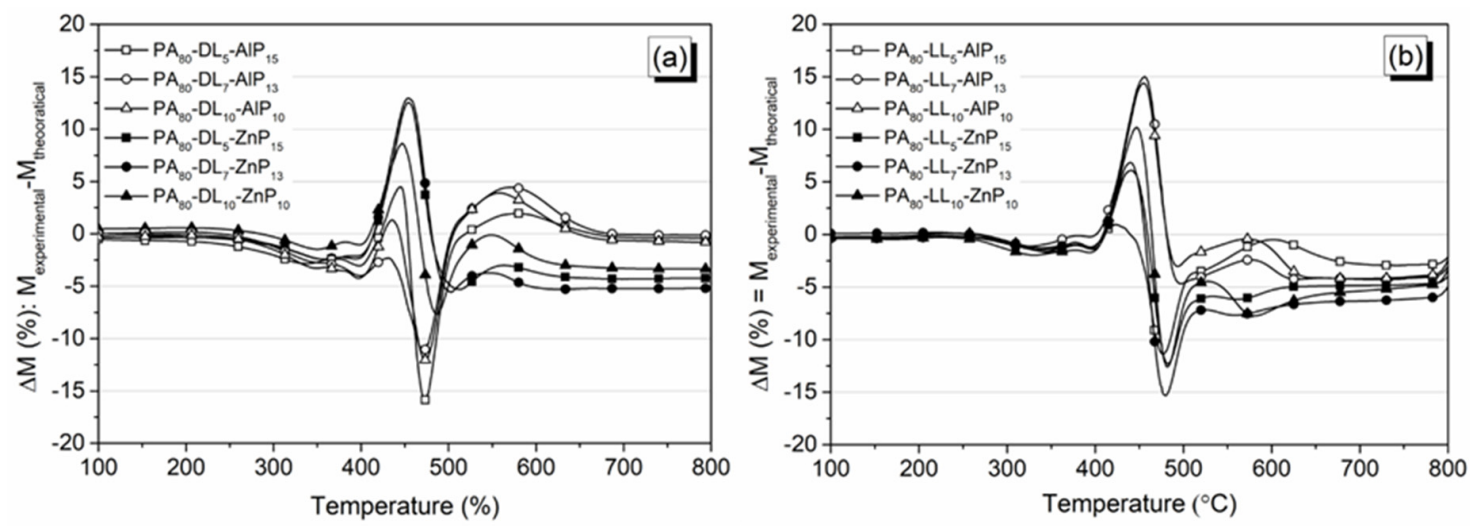

Figure 5. Curves of residual mass loss difference for polyamide 11 (PA11) ternary blends with lignosulphate lignin (LL) (a) and with kraft lignin (DL) (b) in air.

Table 2. Thermogravimetric data for polyamide 11 (PA11) and its blends in $\mathrm{N}_{2}$ and air.

\begin{tabular}{|c|c|c|c|c|c|c|c|c|c|c|}
\hline Samples & $\begin{array}{l}T_{5 \%} \% \\
\left({ }^{\circ} \mathrm{C}\right)\end{array}$ & $\begin{array}{l}T_{\max } \\
\left({ }^{\circ} \mathrm{C}\right)\end{array}$ & $\begin{array}{l}\text { MMLR } \\
\text { (\%/min) }\end{array}$ & $\begin{array}{c}\mathbf{R}_{\operatorname{Exp}}{ }^{1} \\
700^{\circ} \mathrm{C} \\
(\%)\end{array}$ & $\underset{(\%)}{\mathrm{R}_{\mathrm{Cal}}{ }^{1}}$ & $\begin{array}{c}T_{\max 1} \\
\left({ }^{\circ} \mathrm{C}\right)\end{array}$ & $\begin{array}{c}T_{\max 2} \\
\left({ }^{\circ} \mathrm{C}\right)\end{array}$ & $\begin{array}{l}\text { MMLR } \\
(\% / \mathrm{min})\end{array}$ & $\begin{array}{c}R_{\operatorname{Exp}}{ }^{1} \\
700^{\circ} \mathrm{C} \\
(\%)\end{array}$ & $\begin{array}{c}\mathrm{R}_{\mathrm{Cal}}{ }^{1} \\
(\%)\end{array}$ \\
\hline \multicolumn{4}{|c|}{ Atmosphere: Nitrogen } & \multicolumn{7}{|c|}{ Atmosphere: Air } \\
\hline PA11 & 396 & 423 & 2 & 1 & - & 454 & 574 & 1.3 & 2 & - \\
\hline $\mathrm{PA}_{80}-\mathrm{LL}_{5}-\mathrm{ZnP}_{15}$ & 373 & 472 & 2.4 & 5.8 & 6.7 & 464 & 553 & 1.8 & 7.6 & 12.5 \\
\hline $\mathrm{PA}_{80}-\mathrm{LL}_{7}-\mathrm{ZnP}_{13}$ & 364 & 467 & 2 & 8.2 & 7.5 & 462 & 543 & 2 & 6 & 12.3 \\
\hline $\mathrm{PA}_{80}-\mathrm{LL}_{10}-\mathrm{ZnP}_{10}$ & 326 & 465 & 1.8 & 12.7 & 8.6 & 465 & 559 & 2.2 & 6.8 & 12.1 \\
\hline $\mathrm{PA}_{80}-\mathrm{LL}_{5}-\mathrm{AlP}_{15}$ & 363 & 468 & 1.7 & 5.5 & 6.2 & 460 & 611 & 1.6 & 7.1 & 10.0 \\
\hline $\mathrm{PA}_{80}-\mathrm{LL}_{7}-\mathrm{AlP}_{13}$ & 349 & 470 & 1.6 & 7.6 & 7.1 & 472 & 610 & 1.8 & 5.9 & 10.2 \\
\hline $\mathrm{PA}_{80}-\mathrm{LL}_{10}-\mathrm{AlP}_{10}$ & 330 & 445 & 1.5 & 10.7 & 8.3 & 470 & 612 & 1.7 & 6.2 & 10.4 \\
\hline $\mathrm{PA}_{80}-\mathrm{DL}_{5}-\mathrm{ZnP}_{15}$ & 359 & 473 & 2 & 5.4 & 5.8 & 468 & 573 & 1.7 & 5.8 & 10.1 \\
\hline $\mathrm{PA}_{80}-\mathrm{DL}_{7}-\mathrm{ZnP}_{13}$ & 347 & 472 & 1.8 & 6.4 & 6.3 & 474 & 577 & 1.6 & 3.8 & 9.0 \\
\hline $\mathrm{PA}_{80}-\mathrm{DL}_{10}-\mathrm{ZnP}_{10}$ & 339 & 453 & 1.6 & 8.9 & 6.9 & 462 & 564 & 1.7 & 4.1 & 7.4 \\
\hline $\mathrm{PA}_{80}-\mathrm{DL}_{5}-\mathrm{AlP}_{15}$ & 334 & 469 & 1.7 & 5.7 & 5.4 & 458 & 601 & 2.2 & 7.3 & 7.6 \\
\hline $\mathrm{PA}_{80}-\mathrm{DL}_{7}-\mathrm{AlP}_{13}$ & 325 & 470 & 1.6 & 7.4 & 5.9 & 455 & 604 & 1.7 & 6.8 & 6.9 \\
\hline $\mathrm{PA}_{80}-\mathrm{DL}_{10}-\mathrm{AlP}_{10}$ & 313 & 457 & 1.5 & 7.8 & 6.6 & 455 & 583 & 1.6 & 5.1 & 5.7 \\
\hline
\end{tabular}

\subsection{Flammability Behavior}

The results of the UL94 tests for PA11 and the ternary blends are summarized in Table 3, and the typical pictures of the specimens left after the tests are shown in Figure 6. However, the UL94 tests data for the binary blends are reported in Table S2 (Supporting information). Dripping was observed in all the blends, except $\mathrm{PA}_{80}-\mathrm{AlP}_{20}$, which improves the flame-retardant performance and achieves self-extinction (V-0 rating); further, no melt dripping is observed. This finding can be ascribed to the release of phosphinic acid and phosphinate compounds in the gas phase, which dilutes the fuel. Conversely, $20 \mathrm{wt} \% \mathrm{ZnP}$ loading in PA11 is not sufficient to improve flame retardancy and UL94 rating; in fact, $\mathrm{PA}_{80}-\mathrm{ZnP}_{20}$ specimens lead to high flammability and dripping (Table S2, Supporting information).

In addition to this, the presence of LL in ternary blends decreases the total combustion time. However, the best flame-retardant results were obtained with PA-LL-ZnP blends, specifically with 7 and 10 wt \% loading of LL (i.e., for $\mathrm{PA}_{80}-\mathrm{LL}_{7}-\mathrm{ZnP}_{13}, \mathrm{PA}_{80}-\mathrm{LL}_{10}-\mathrm{ZnP}_{10}$ blends), which achieve 
self-extinction and V-1 classification. Interestingly, $\mathrm{PA}_{80}-\mathrm{LL}_{10}-\mathrm{ZnP}_{10}$ shows the minimum $\mathrm{ZnP}$ loading. It is expected that the presence of sulfonate functionality in LL may lead to the formation of a thermally stable compound. In fact, increasing $\mathrm{ZnP}$ loadings deteriorate the performances, as $\mathrm{ZnP}$ promotes melt dripping phenomena [34]. As regards to the flame-retardant action, it was assumed that $\mathrm{ZnP}$ decomposition produces phosphinate compounds in the gas phase that can release $\mathrm{P}-\mathrm{O} \bullet$ radicals: this latter can act as radical scavengers and lead to flame inhibition through radical trapping, hence improving the flame retardancy of blends $[35,36]$. These results demonstrate that the proposed LL/ZnP combinations are potentially effective. Conversely, the presence of DL in ternary blends does not show significant improvement under UL94 tests, as all these ternary blends have a V-2 classification. This behavior was attributed to the rapid decomposition of DL in air; further, DL decomposed mainly $\left(T_{\max 1}\right)$ during the decomposition of PA11.

Table 3. UL94 vertical flame spread test data for polyamide 11 (PA11) and its blends.

\begin{tabular}{|c|c|c|c|c|c|c|}
\hline Samples & $\begin{array}{c}1^{\text {st }} \text { Flame } t_{1} \\
\text { (s) }\end{array}$ & $\begin{array}{c}2^{\text {nd }} \text { Flame } t_{2} \\
\text { (s) }\end{array}$ & $\begin{array}{l}\text { Combustion } \\
\text { time }\left(t_{1}+t_{2}\right)\end{array}$ & $\begin{array}{l}\text { Cotton } \\
\text { Ignition }\end{array}$ & Dripping & Rating \\
\hline PA11 & $11 \pm 1$ & $7 \pm 1$ & $18 \pm 1$ & Yes & Yes & $\mathrm{V} 2$ \\
\hline $\mathrm{PA}_{80}-\mathrm{LL}_{5}-\mathrm{ZnP}_{15}$ & $11 \pm 1$ & $3 \pm 1$ & $14 \pm 1$ & Yes & Yes & $\mathrm{V} 2$ \\
\hline $\mathrm{PA}_{80}-\mathrm{LL}_{7}-\mathrm{ZnP}_{13}$ & $4 \pm 1$ & $3 \pm 1$ & $7 \pm 1$ & No & Yes & $\mathrm{V} 1$ \\
\hline $\mathrm{PA}_{80}-\mathrm{LL}_{10}-\mathrm{ZnP}_{10}$ & $6 \pm 1$ & $3 \pm 1$ & $9 \pm 1$ & No & Yes & V1 \\
\hline $\mathrm{PA}_{80}-\mathrm{LL}_{5}-\mathrm{AlP}_{15}$ & $16 \pm 1$ & $6 \pm 2$ & $22 \pm 1$ & Yes & Yes & $\mathrm{V} 2$ \\
\hline $\mathrm{PA}_{80}-\mathrm{LL}_{7}-\mathrm{AlP}_{13}$ & $24 \pm 2$ & $4 \pm 1$ & $28 \pm 2$ & Yes & Yes & $\mathrm{V} 2$ \\
\hline $\mathrm{PA}_{80}-\mathrm{LL}_{10}-\mathrm{AlP}_{10}$ & $8 \pm 1$ & $4 \pm 1$ & $12 \pm 2$ & Yes & Yes & $\mathrm{V} 2$ \\
\hline $\mathrm{PA}_{80}-\mathrm{DL}_{5}-\mathrm{ZnP}_{15}$ & $10 \pm 1$ & $4 \pm 1$ & $14 \pm 2$ & Yes & Yes & $\mathrm{V} 2$ \\
\hline $\mathrm{PA}_{80}-\mathrm{DL}_{7}-\mathrm{ZnP}_{13}$ & $11 \pm 1$ & $4 \pm 1$ & $15 \pm 2$ & Yes & Yes & $\mathrm{V} 2$ \\
\hline $\mathrm{PA}_{80}-\mathrm{DL}_{10}-\mathrm{ZnP}_{10}$ & $7 \pm 1$ & $3 \pm 1$ & $10 \pm 1$ & Yes & Yes & $\mathrm{V} 2$ \\
\hline $\mathrm{PA}_{80}-\mathrm{DL}_{5}-\mathrm{AlP}_{15}$ & $22 \pm 2$ & $5 \pm 1$ & $27 \pm 2$ & Yes & Yes & $\mathrm{V} 2$ \\
\hline $\mathrm{PA}_{80}-\mathrm{DL}_{7}-\mathrm{AlP}_{13}$ & $19 \pm 1$ & $4 \pm 1$ & $23 \pm 2$ & Yes & Yes & $\mathrm{V} 2$ \\
\hline $\mathrm{PA}_{80}-\mathrm{DL}_{10}-\mathrm{AlP}_{10}$ & $18 \pm 1$ & $3 \pm 1$ & $20 \pm 1$ & Yes & Yes & $\mathrm{V} 2$ \\
\hline
\end{tabular}

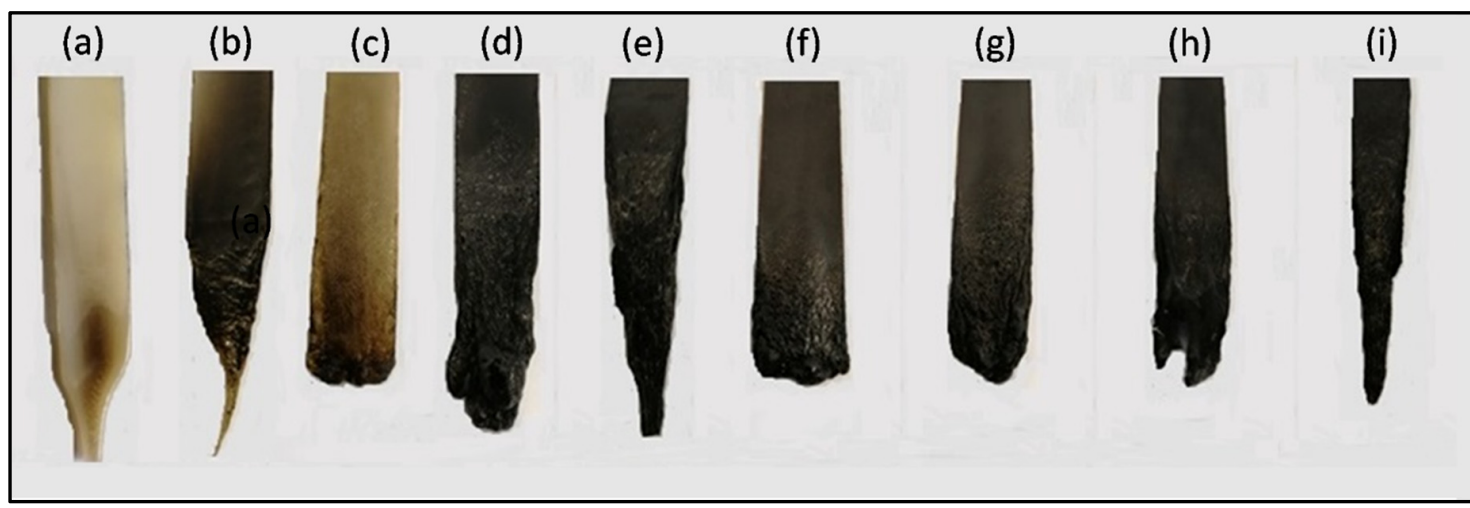

Figure 6. Pictures of PA11 blends specimen left after UL 94 vertical flame test. (a) PA11; (b) $\mathrm{PA}_{80}-\mathrm{ZnP}_{20}$; (c) $\mathrm{PA}_{80}-\mathrm{AlP}_{20}$; (d) $\mathrm{PA}_{80}-\mathrm{LL}_{20}$; (e) $\mathrm{PA}_{80}-\mathrm{DL}_{20}$; (f) $\mathrm{PA}_{80}-\mathrm{LL}_{10}-\mathrm{ZnP}_{10}$; (g) $\mathrm{PA}_{80}-\mathrm{DL}_{10}-\mathrm{ZnP}_{10}$; (h) $\mathrm{PA}_{80}-\mathrm{DL}_{10}-\mathrm{ZnP}_{10} ;$ (i) $\mathrm{PA}_{80}-\mathrm{DL}_{10}-\mathrm{AlP}_{10}$.

\subsection{Forced-Combustion Behavior}

In order to simulate the fire hazards under a real fire scenario, cone calorimetry tests were performed using $35 \mathrm{~kW} / \mathrm{m}^{2}$ heat flux and $60 \mathrm{~mm}$ separation length. Since the distance from the sample surface to the spark igniter increases, the volatiles leaving from the heated sample and the oxygen from air have more time to mix before reaching the spark igniter. This is indicated by an increase in time to ignition. The heat release rate (HRR) and total heat release (THR) are potential fire parameters to evaluate the combustion behaviour of a material exposed to certain heat flux $[37,38]$. The HRR and THR curves are shown in Figures 7 and 8 and the cone calorimetry data for PA11 and the ternary 
blends are collected in Table 4. However, heat release curves and the cone calorimetry data for the binary blends are presented in Figure S3 and Table S3 (Supporting information). Figure 7a-d shows the influence of LL with $\mathrm{ZnP} / \mathrm{AlP}$ on HRR and THR. In particular, the ternary blends containing LL and ZnP showed lower TTI as compared to unfilled PA11, as anticipated by TG analyses in air: in fact, the adding of 5 to $10 \mathrm{wt} \% \mathrm{LL}$ strongly reduces its $T_{5 \%}$, promoting, at the same time, the formation of a thermally stable char residue. A similar trend was observed during combustion tests: TTI value decreases with increasing LL content from 5 to $10 \mathrm{wt} \%$ in blends; this finding is attributed to the rapid mass loss of LL taking place before the decomposition of PA11. Besides, PHRR and THR values substantially drop (by $64 \%$ and $22 \%$, respectively) for $\mathrm{PA}_{80}-\mathrm{LL}_{10}-\mathrm{ZnP}_{10}$ blend, due to the formation of a protective char layer in the condensed phase that can effectively delay the heat release during combustion. LL contains sulfonate compounds, which are likely to decompose during combustion, releasing $\mathrm{SO}_{2}$, thus limiting the heat release and originating thermally stable $\mathrm{Na}_{2} \mathrm{SO}_{4}$ in the condensed phase $[33,39]$. It is noteworthy that the LL and $\mathrm{ZnP}$ formulation used in this study showed the enhanced fire performance compared to the cone calorimeter results presented in our previous study with lignin and $\mathrm{ZnP}$ combination [23]. When $\mathrm{ZnP}$ is replaced with AlP, PHRR remarkably decreases up to $230 \mathrm{~kW} / \mathrm{m}^{2}$ for $\mathrm{PA}_{80}-\mathrm{LL}_{10}-\mathrm{AlP}_{10}$. In addition, HRR curve reveals a broad and single peak of HRR, hence indicating the formation of an effective protective char layer. This superior fire-retardant property in forced combustion tests is due to the presence of an efficient aluminum phosphate layer, able to confer stability to the char residue. The increased char residue at the end of the test (Table 4) further confirms the formation of the protective layer.
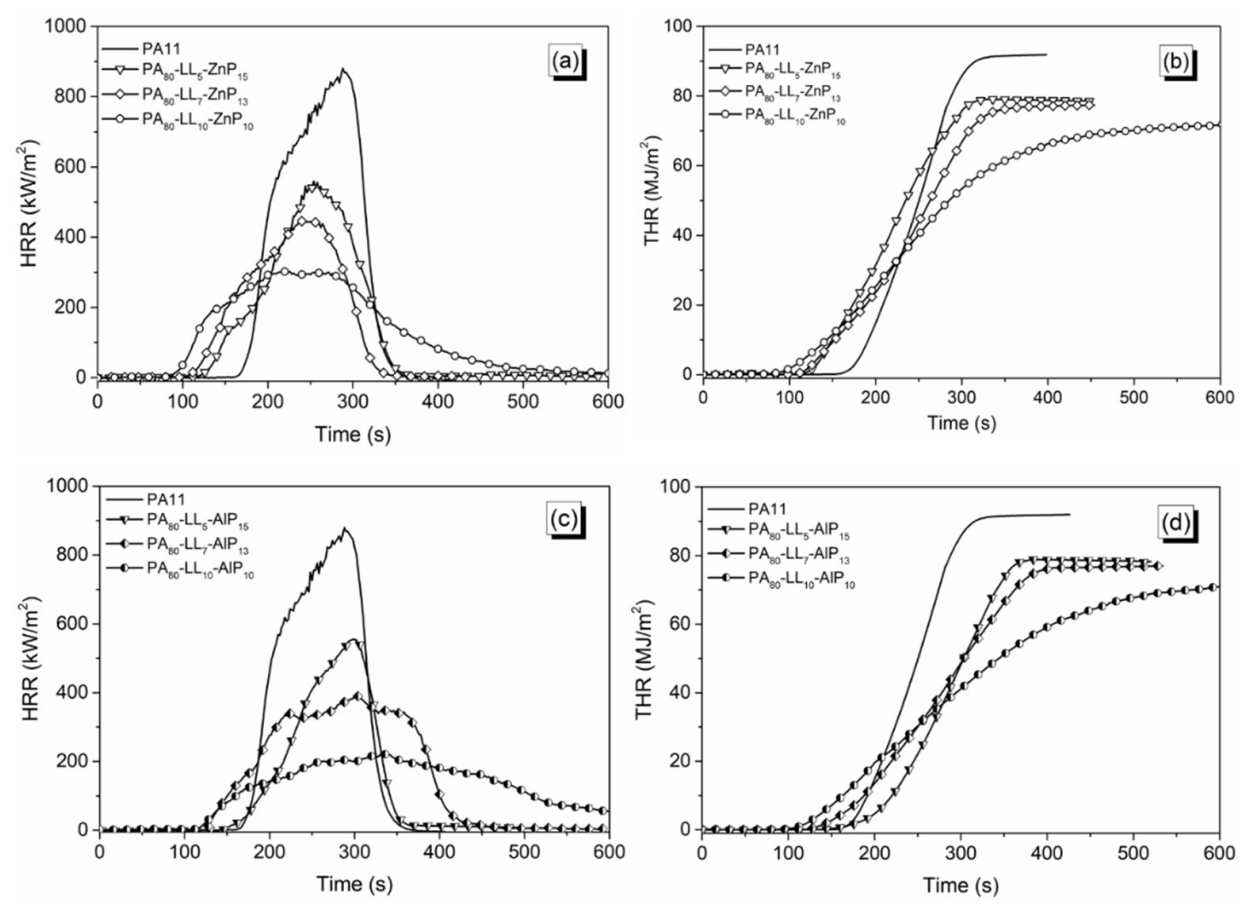

Figure 7. Heat release rate (HRR) and total heat release (THR) curves of polyamide 11 (PA11) blends. (a) and (b) for PA-LL-ZnP blends; (c) and (d) for PA-LL-AlP blends.

Furthermore, Figure 8 shows the influence of $\mathrm{DL}$ and $\mathrm{ZnP} / \mathrm{AlP}$ on HRR and THR. It is worthy to note that, unlike LL lignin, the addition of DL with $\mathrm{ZnP}$ does not show a significant reduction in PHRR and THR. However, a certain reduction in PHRR $(-43 \%)$ is seen when DL content achieves $10 \mathrm{wt} \%$. Besides, the PA-DL-AlP blends show a remarkable reduction of PHRR $(-64 \%)$ and THR $(-22 \%)$ for $\mathrm{PA}_{80}-\mathrm{DL}_{10}-\mathrm{AlP}_{10}$. This is attributed to the presence of AlP, which promotes the formation of a stable char layer acting as a protective barrier, limiting the heat and mass transfer from and to the underlying polymer. 
Flame retardant action can also be confirmed by the effective heat combustion (EHC), which is expressed by the ratio of heat release to mass loss during combustion. EHC reflects the combustion efficiency of flammable volatiles. An obvious gas phase flame retardant action would lead to a noticeable reduction in EHC value as compared to the neat material [40]. Data collected in Table 4 show EHC for PA11 and the ternary blends, while the ternary blends containing 7 and $10 \mathrm{wt} \%$ of the lignins show lower EHC values; in this case, the flame inhibition occurs with an incomplete combustion, thus increasing the smoke and the $\mathrm{CO}$ release (Table 4) in the gas phase.
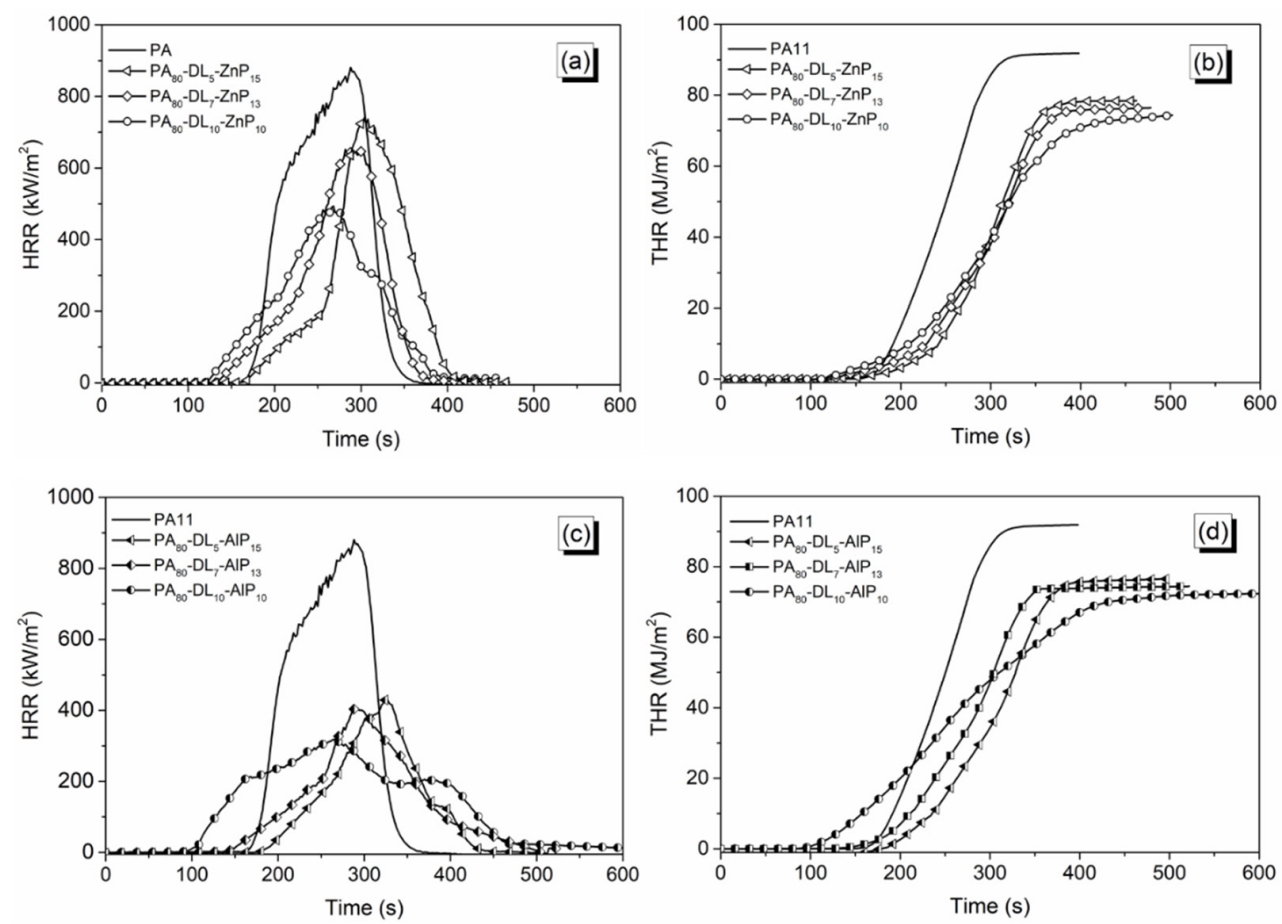

Figure 8. Heat release rate (HRR) and total heat release (THR) curves of polyamide 11 (PA11) blends. (a) and (b) for PA-DL-ZnP blends; (c) and (d) for PA-DL-AlP blends.

Table 4. Cone calorimetry data for polyamide 11 (PA11) and its blends.

\begin{tabular}{|c|c|c|c|c|c|c|c|c|c|c|}
\hline Samples & TTI (s) & $\begin{array}{c}\text { PHRR } \\
\left(\mathrm{kW} / \mathrm{m}^{2}\right)\end{array}$ & $\begin{array}{c}\text { Reduction } \\
(\%)\end{array}$ & $\begin{array}{c}\text { THR } \\
\left(\mathrm{MJ} / \mathrm{m}^{2}\right)\end{array}$ & $\begin{array}{c}\text { EHC } \\
(\mathbf{k J} / \mathrm{g})\end{array}$ & $\begin{array}{c}\text { TSR } \\
\left(\mathrm{m}^{2} / \mathrm{m}^{2}\right)\end{array}$ & $\begin{array}{l}\text { CO } \\
\text { Yield } \\
(\mathrm{g} / \mathrm{kg})\end{array}$ & $\begin{array}{c}\mathrm{CO}_{2} \\
\text { Yield } \\
(\mathrm{kg} / \mathrm{kg})\end{array}$ & $\mathrm{CO}_{2} / \mathrm{CO}$ & $\begin{array}{c}\text { Residue } \\
(\%)\end{array}$ \\
\hline PA11 & $154 \pm 3$ & $884 \pm 4$ & - & $92 \pm 4$ & $33.8 \pm 0.6$ & $1033 \pm 1$ & $33 \pm 1$ & $2.6 \pm 0.1$ & 79 & $0.6 \pm 0.1$ \\
\hline $\mathrm{PA}_{80}-\mathrm{LL}_{7}-\mathrm{ZnP}_{13}$ & $92 \pm 9$ & $443 \pm 21$ & 50 & $77 \pm 4$ & $28.8 \pm 0.7$ & $1652 \pm 151$ & $92 \pm 1$ & $2.1 \pm 0.1$ & 23 & $6.2 \pm 0.2$ \\
\hline $\mathrm{PA}_{80}-\mathrm{LL}_{10}-\mathrm{ZnP}_{10}$ & $86 \pm 9$ & $315 \pm 11$ & 64 & $73 \pm 2$ & $28.4 \pm 0.4$ & $1691 \pm 26$ & $72 \pm 2$ & $2.0 \pm 0.1$ & 28 & $8.5 \pm 0.3$ \\
\hline $\mathrm{PA}_{80}-\mathrm{LL}_{5}-\mathrm{AlP}_{15}$ & $142 \pm 11$ & $554 \pm 33$ & 37 & $78 \pm 6$ & $30.3 \pm 1$ & $1959 \pm 28$ & $98 \pm 3$ & $1.9 \pm 0.1$ & 19 & $5.8 \pm 0.3$ \\
\hline $\mathrm{PA}_{80}-\mathrm{DL}_{5}-\mathrm{ZnP}_{15}$ & $150 \pm 18$ & $740 \pm 23$ & 16 & $79 \pm 2$ & $29.6 \pm 1.3$ & $1720 \pm 36$ & $71 \pm 3$ & $2.2 \pm 0.1$ & 31 & $3.8 \pm 0.2$ \\
\hline $\mathrm{PA}_{80}-\mathrm{DL}_{7}-\mathrm{ZnP}_{13}$ & $128 \pm 14$ & $678 \pm 36$ & 23 & $77 \pm 3$ & $30.2 \pm 0.4$ & $1800 \pm 88$ & $73 \pm 4$ & $2.1 \pm 0.1$ & 29 & $5.2 \pm 1.5$ \\
\hline $\mathrm{PA}_{80}-\mathrm{DL}_{10}-\mathrm{ZnP}_{10}$ & $116 \pm 13$ & $500 \pm 48$ & 43 & $75 \pm 7$ & $30.3 \pm 1.2$ & $1745 \pm 62$ & $61 \pm 6$ & $2.1 \pm 0.1$ & 34 & $8.2 \pm 0.5$ \\
\hline $\mathrm{PA}_{80}-\mathrm{DL}_{5}-\mathrm{AlP}_{15}$ & $174 \pm 14$ & $424 \pm 39$ & 42 & $76 \pm 4$ & $28 \pm 1$ & $1819 \pm 40$ & $99 \pm 2$ & $2.0 \pm 0.1$ & 20 & $7.7 \pm 0.5$ \\
\hline $\mathrm{PA}_{80}-\mathrm{DL}_{7}-\mathrm{AlP}_{13}$ & $140 \pm 12$ & $406 \pm 34$ & 54 & $74 \pm 5$ & $31 \pm 1$ & $1929 \pm 45$ & $90 \pm 3$ & $2.0 \pm 0.1$ & 22 & $8.6 \pm 0.5$ \\
\hline $\mathrm{PA}_{80}-\mathrm{DL}_{10}-\mathrm{AlP}_{10}$ & $95 \pm 7$ & $320 \pm 10$ & 64 & $72 \pm 1$ & $29 \pm 1.3$ & $1967 \pm 68$ & $86 \pm 5$ & $2.1 \pm 0.1$ & 24 & $10.4 \pm 0.5$ \\
\hline
\end{tabular}

\subsection{Smoke and CO Release}

The release of smoke and $\mathrm{CO}$ during combustion is not only a key fire hazard, but also an indication of the flame-retardant mechanism. For instance, a significant increase in the smoke release and $\mathrm{CO}$ amount is originated by incomplete oxidation of gaseous products, which indicates a flame inhibition action by radical trapping reactions taking place in the gas phase. Alternatively, a decrease in smoke release indicates a better-ventilated combustion process, in which the flame retardancy is dominated by fuel dilution and/or thermal barrier [35,41]. Therefore, total smoke release (TSR), 
$\mathrm{CO}$ and $\mathrm{CO}_{2}$ total yield, and $\mathrm{CO}_{2} / \mathrm{CO}$ yield were assessed; the corresponding data are collected in Table 4. First of all, the $\mathrm{CO}_{2}$ yield is practically similar for all the blends. As compared to PA11, binary blends with $\mathrm{ZnP}$ or AlP increase the smoke release and $\mathrm{CO}$ yield and lower the $\mathrm{CO}_{2} / \mathrm{CO}$ yield, hence indicating the incomplete oxidation of gaseous products. Conversely, the incorporation of LL and DL lowers TSR and $\mathrm{CO}$ yield and increase $\mathrm{CO}_{2} / \mathrm{CO}$ yield, also confirming the extended oxidation of the evolved gaseous products (Figure S4, Supporting information).

On the other hand, the combination of lignin and phosphinate worsens the smoke parameters, confirming the occurrence of incomplete combustion. However, increasing the lignin content reduces the $\mathrm{CO}$ release, which is attributed to the more complete oxidation of evolved volatile products. Figure 9 shows the influence of LL mixed with flame retardants on $\mathrm{CO}$ and $\mathrm{CO}_{2}$ evolution. Interestingly, the blends containing $10 \mathrm{wt} \%$ of both fillers show the lowest $\mathrm{CO}$ release with respect to other ternary blends: more specifically, $\mathrm{PA}_{80}-\mathrm{LL}_{10}-\mathrm{ZnP}_{10}$ blend significantly lowers the peak of $\mathrm{CO}$ release up to $300 \mathrm{ppm}$ without compromising the other fire-retardant properties. This finding can be ascribed to the interactions taking place between LL and $\mathrm{ZnP}$ in the ternary blend, which leads to extended oxidation of the evolved gaseous products as well as to the formation of a protective char in the condensed phase. Conversely, the peak of $\mathrm{CO}$ evolution reported in our previous study with lignin and $\mathrm{ZnP}$ combination showed a slightly higher, up to $500 \mathrm{ppm}$, for the same blend (i.e., $10 \mathrm{wt} \%$ concentration of both additives) [23]. Based on results, it can be concluded that the combination of lignin and phosphinate promotes the smoke and CO release; however, high lignin loading remarkably reduces CO release, hence minimize the smoke toxicity.
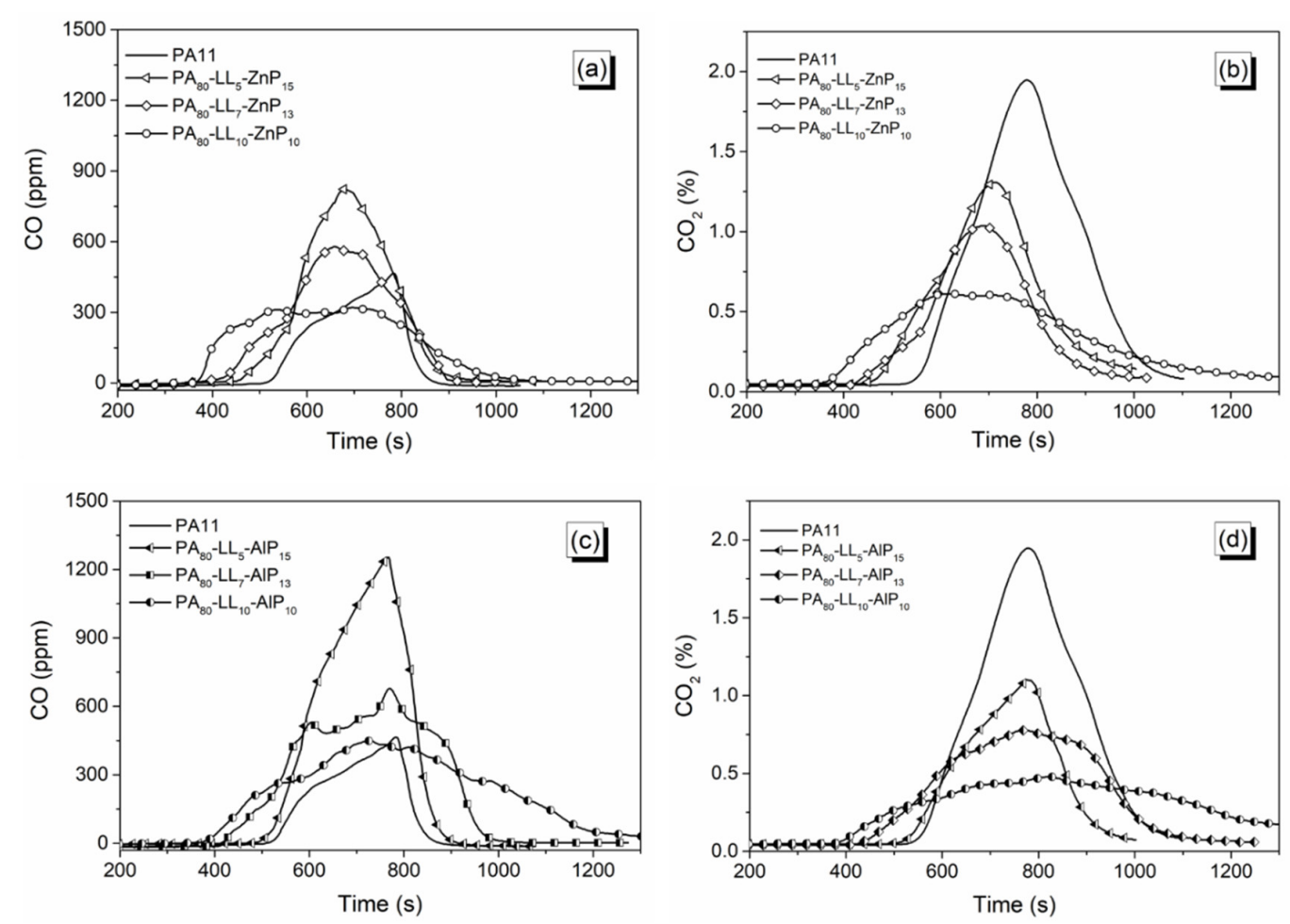

Figure 9. $\mathrm{CO}$ and $\mathrm{CO}_{2}$ evolution during combustion. (a) and (b) for PA-LL-ZnP blends; (c) and (d) for PA-LL-AlP blends.

\subsection{Morphology of Char Residue}

Figure 10 shows the pictures of residues obtained after forced combustion tests. It is clearly observed (Figure 10a) that the residue from PA11 is very thin and practically negligible. Similarly, PA11 with ZnP (Figure 10b) shows a mechanically thin and non-charring characteristic. However, $\mathrm{PA}_{80}-\mathrm{AlP}_{20}$ slightly increases the residue (Figure 10c), although the presence of cracks and insufficient residue leads to the formation of a weak protective layer. Besides, the binary blends of lignin (LL 
and DL) display a higher char residue formation: in particular, $\mathrm{PA}_{80}-\mathrm{LL}_{20}$ (Figure $10 \mathrm{~d}$ ) gives rise to a coherent and compact char layer formation, which protect the material against heat flux and reducing the release of flammable and non-flammable gases throughout the polymer. However, the presence of cracks deteriorates the performance. Similarly, the char residue of $\mathrm{PA}_{80}-\mathrm{DL}_{20}$ shows a loose and porous surface with many cracks (Figure 10e). Interestingly, the combination of lignin and phosphinate not only increases the char residue but also leads to the formation of a stable char layer with barrier features against heat flux and release of combustible gases. In particular, the addition of LL with ZnP/AlP (Figure 10f,g) shows a compact and protective layer due to sufficient char formation. Conversely, ternary blends of DL show a thin char layer and relatively loose structure with many cracks; more specifically, $\mathrm{PA}_{80}-\mathrm{DL}_{10}-\mathrm{ZnP}_{10}$ (Figure 10i) gives a fragile and mechanically weak char layer. In order to further investigate the microscopic morphology and structure of the charred layer, the top surface of char residues was observed by SEM (Figure 11a-d). It can be observed that the surface morphology of residue from $\mathrm{PA}_{80}-\mathrm{LL}_{10}-\mathrm{AlP}_{10}$ (Figure 11a) appears denser and more compact due to the increased char formation and interaction between LL and AlP leading to a stable protective char layer, which contributes to improved flame retardancy. Furthermore, EDX analysis reveals the presence of $\mathrm{C}, \mathrm{O}$, $\mathrm{Na}, \mathrm{Al}$, and $\mathrm{P}$, which results in a more compact char residue. Similar char residue morphology with $\mathrm{AlP}$ is reported $[42,43]$. As shown in Figure $11 \mathrm{~b}, \mathrm{PA}_{80}-\mathrm{LL}_{10}-\mathrm{ZnP}_{10}$ presents a relatively less dense and compact structure in comparison with $\mathrm{PA}_{80}-\mathrm{LL}_{10}-\mathrm{AlP}_{10}$, although compact char layer is present with some holes on the surface. In contrast, the surface morphology of residue from DL containing blends (Figure 11c,d) does not form an intact char layer due to insufficient char formation during combustion; as a consequence, a loose and porous structure is formed.
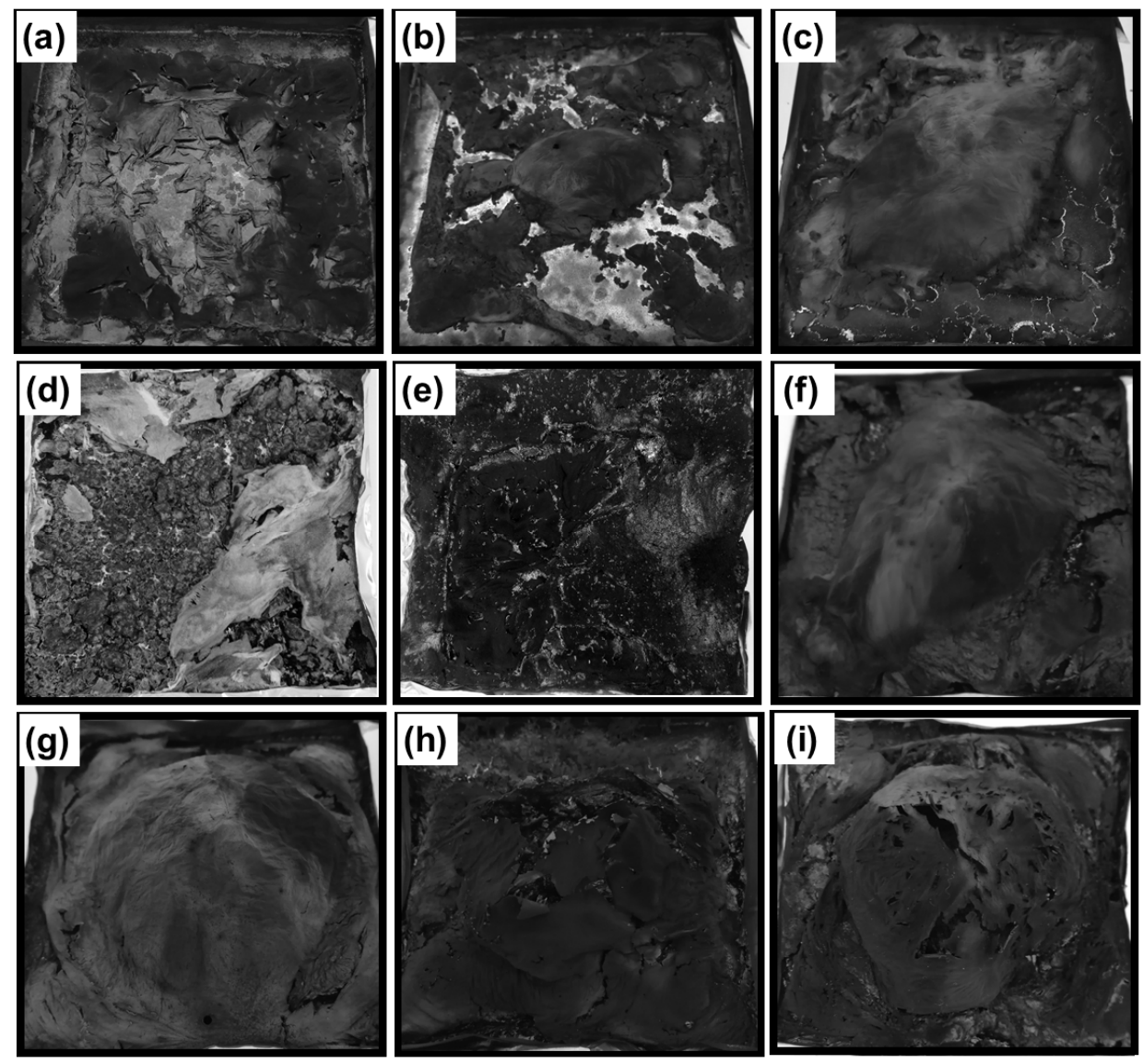

Figure 10. Pictures of char residues collected at the end of cone calorimetry test: (a) unfilled polyamide 11 (PA11); (b) $\mathrm{PA}_{80}-\mathrm{ZnP}_{20}$; (c) $\mathrm{PA}_{80}-\mathrm{AlP}_{20}$; (d) $\mathrm{PA}_{80}-\mathrm{LL}_{20}$; (e) $\mathrm{PA}_{80}-\mathrm{DL}_{20}$; (f) $\mathrm{PA}_{80}-\mathrm{LL}_{10}-\mathrm{AlP}_{10}$; (g) $\mathrm{PA}_{80}-\mathrm{LL}_{10}-\mathrm{ZnP}_{10} ;$ (h) $\mathrm{PA}_{80}-\mathrm{DL}_{10}-\mathrm{AlP}_{10}$ and (i) $\mathrm{PA}_{80}-\mathrm{DL}_{10}-\mathrm{ZnP}_{10}$ blends. 

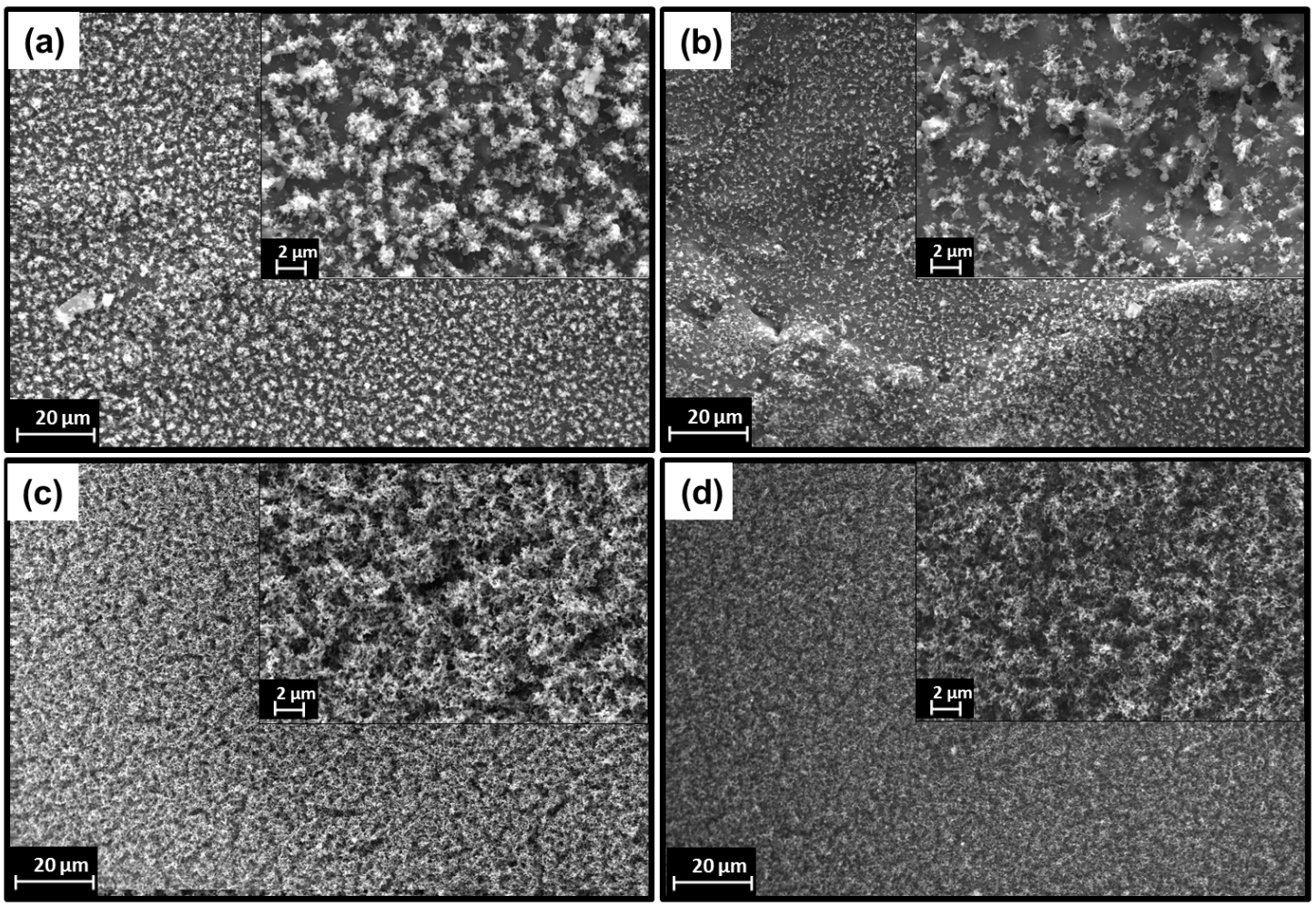

Figure 11. Scanning Electron Microscopy (SEM) micrographs of char residue surface after forced combustion for (a) $\mathrm{PA}_{80}-\mathrm{LL}_{10}-\mathrm{AlP}_{10}$; (b) $\mathrm{PA}_{80}-\mathrm{LL}_{10}-\mathrm{ZnP}_{10}$; (c) $\mathrm{PA}_{80}-\mathrm{DL}_{10}-\mathrm{AlP}_{10}$ and (d) $\mathrm{PA}_{80}-\mathrm{DL}_{10}-\mathrm{ZnP}_{10}$ blends at $1000 \times$ and $5000 \times$ magnification.

\section{Conclusions}

So as to advance the exploitation of industrial lignin, in this work, different lignins, i.e., LL and DL, were combined with phosphinate ( $\mathrm{ZnP}$ and AlP) flame retardants in PA11. Different flame retarded blends were prepared using melt extrusion. The influence of the presence of lignin with phosphinate on the thermal and fire behavior was thoroughly assessed by TG analyses, UL 94 vertical flame spread, and cone calorimetry tests. SEM analyses of the blends showed that the addition of lignin and phosphinates up to $20 \mathrm{wt} \%$ minimizes the particle size due to the thermal mixing; in addition, EDX elemental mapping revealed a suitable dispersion of lignin and phosphinate within the polymer matrix. However, some small $(<10 \mu \mathrm{m})$ agglomerates were observed in AlP containing blends. TG analyses showed that, regardless of its type, the incorporation of lignin in the ternary blends increased the thermal stability of PA11, promoting the obtainment of a stable char residue at the end of the tests. Through UL 94 vertical flame spread tests, it was possible to demonstrate that the combination of LL with $\mathrm{ZnP}$ effectively improves the flame-retardant properties by reducing total combustion time. More specifically, $\mathrm{PA}_{80}-\mathrm{LL}_{10}-\mathrm{ZnP}_{10}$ and $\mathrm{PA}_{80}-\mathrm{LL}_{7}-\mathrm{ZnP}_{13}$ achieved self-extinction and $\mathrm{V}-1$ rating. Furthermore, in forced combustion test the interactions between lignin and phosphinate promoted a remarkable reduction of PHRR and THR. In particular, the best fire-retardant performance was found by combining LL with AlP (i.e., $\left.\mathrm{PA}_{80}-\mathrm{LL}_{10}-\mathrm{AlP}_{10}\right)$, resulting in a strong reduction of PHRR $(-74 \%)$ and THR $(-22 \%)$ values. On the other hand, smoke parameters, namely TSR and CO yield, increased in ternary blends; however, increasing the lignin loading effectively reduced the $\mathrm{CO}$ and $\mathrm{CO}_{2} / \mathrm{CO}$ yield compared to PA11. Particularly, $\mathrm{PA}_{80}-\mathrm{LL}_{10}-\mathrm{ZnP}_{10}$ blend shows minimum $\mathrm{CO}$ evolution without affecting flame retardancy. The morphology of char residue showed that the formation of compact char layer is primarily responsible for the improved flame-retardant properties. In conclusion, from an overall point of view, the direct use of industrial lignin with phosphinate in PA11 seems to be quite promising as far as fire retardancy is concerned, also considering the "biobased" character of both the polymer matrix and the lignins. 
Supplementary Materials: The following are available online at http:/ / www.mdpi.com/2073-4360/11/1/180/s1, Figure S1: SEM images showing particle size distribution of pristine material, (a) ZnP, (b) AlP, (c) DL, (d) LL. Figure S2. TG curves of unfilled PA11 and neat materials in N2 (a) and air (b), Figure S3. HRR and THR curves of PA11 and the binary blends, (a) and (b) PA80-LL20, (c) and (d) PA80-DL20, (e) and (f) PA80-ZnP20, (g) and (h) PA80-AlP20 blends, Figure S4. CO and CO2 evolution during combustion for PA11 and the binary blends, (a) and (b) PA80-LL20, (c) and (d) PA80-ZnP20, (e) and (f) PA80-AlP20 blends. Table S1: Thermogravimetric data for PA11 and its blends in N2 and air. Table S2. UL94 vertical flame spread test data for PA11 and the binary blends, Table S3. Cone calorimetry data for PA11 and its binary blends.

Author Contributions: Conceptualization, S.G. and F.S.; methodology, N.M., A.C., F.R., S.G. and F.S.; software, N.M., A.C., F.R., S.G. and F.S.; validation, N.M., A.C., F.R., S.G. and F.S.; formal analysis, N.M., A.C., F.R., S.G. and F.S.; investigation, N.M., A.C., F.R., S.G. and F.S.; resources, N.M.; data curation, N.M.; writing-original draft preparation, N.M.; writing-review and editing, N.M., A.C., F.R., S.G. and F.S.; visualization, A.C., F.R., S.G. and F.S.; supervision, A.C., F.R., S.G., F.S. and J.G.; project administration, S.G., F.S. and J.G.; funding acquisition, S.G., F.S. and J.G.

Funding: The authors gratefully acknowledge the financial support of this research work by the European Commission's Erasmus Mundus joint doctorate program under the framework of Sustainable Management \& Design for Textiles (SMDTex) (grant number 2015-1594/001-001-EMJD). The APC was funded by ENSAIT, GEMTEX.

Conflicts of Interest: The authors declare no conflict of interest. The funders had no role in the design of the study; in the collection, analyses, or interpretation of data; in the writing of the manuscript, or in the decision to publish the results.

\section{References}

1. Morgan, A.B.; Wilkie, C.A. Non-Halogenated Flame Retardant Handbook; Scrivener Publishing: Beverly, MA, USA, 2014.

2. Rilsan ${ }^{2}$ PA11: Created from a Renewable Source; Arkema Inc.: Colombes, France, 2012.

3. Kuciel, S.; Kuzniar, P.; Liber-Kneć, A. Polyamides from renewable sources as matrices of short fiber reinforced biocomposites. Polimery 2012, 57, 627-634. [CrossRef]

4. Holbery, J.; Houston, D. Natural-Fiber-Reinforced Polymer Composites in Automotive Applications. JOM 2006, 58, 80-86. [CrossRef]

5. da Costa, A.P.; Botelho, E.C.; Costa, M.L.; Narita, N.E.; Tarpani, J.R. A review of welding technologies for thermoplastic composites in aerospace applications. J. Aerosp. Technol. Manag. 2012, 4, 255-265. [CrossRef]

6. Lignin Products Global Market Size, Sales Data 2017-2022; Reuters: London, UK, 2017; Available online: https: / / www.reuters.com/brandfeatures/venture-capital/article?id=4789 (accessed on 2 August 2018).

7. Laurichesse, S.; Avérous, L. Chemical modification of lignins: Towards biobased polymers. Prog. Polym. Sci. 2014, 39, 1266-1290. [CrossRef]

8. Polat, Y.; Stojanovska, E.; Negawo, T.A. Lignin as an Additive for Advanced Composites. Green Biocompos. 2017, 71-89. [CrossRef]

9. Cicala, G.; Saccullo, G.; Blanco, I.; Samal, S.; Battiato, S.; Dattilo, S.; Saake, B. Polylactide/lignin blends: Effects of processing conditions on structure and thermo-mechanical properties. J. Therm. Anal. Calorim. 2017, 130, 515-524. [CrossRef]

10. Thakur, V.K.; Thakur, M.K.; Raghavan, P.; Kessler, M.R. Progress in Green Polymer Composites from Lignin for Multifunctional Applications: A Review. ACS Sustain. Chem. Eng. 2014, 2, 1072-1092. [CrossRef]

11. Fernandes, D.M.; Hechenleitner, A.A.W.; Job, A.E.; Radovanocic, E.; Pineda, E.A.G. Thermal and photochemical stability of poly(vinyl alcohol)/modified lignin blends. Polym. Degrad. Stab. 2006, 91, 1192-1201. [CrossRef]

12. Mousavioun, P.; Doherty, W.O.S.; George, G. Thermal stability and miscibility of poly(hydroxybutyrate) and soda lignin blends. Ind. Crops Prod. 2010, 32, 656-661. [CrossRef]

13. Blanco, I.; Cicala, G.; Latteri, A.; Saccullo, G.; El-Sabbagh, A.M.M.; Ziegmann, G. Thermal characterization of a series of lignin-based polypropylene blends. J. Therm. Anal. Calorim. 2017, 127, 147-153. [CrossRef]

14. Réti, C.; Casetta, M.; Duquesne, S.; Bourbigot, S.; Delobel, R. Flammability properties of intumescent PLA including starch and lignin. Polym. Adv. Technol. 2008, 19, 628-635. [CrossRef]

15. Lu, W.; Li, Q.; Zhang, Y.; Yu, H.; Hirose, S.; Hatakeyama, H.; Matsumoto, Y. Lignosulfonate/APP IFR and its flame retardancy in lignosulfonate-based rigid polyurethane foams. J. Wood Sci. 2018, 64, 287-293. [CrossRef] 
16. Mandlekar, N.; Cayla, A.; Rault, F.; Giraud, S.; Salaün, F.; Malucelli, G.; Guan, J. Thermal Stability and Fire Retardant Properties of Polyamide 11 Microcomposites Containing Different Lignins. Ind. Eng. Chem. Res. 2017, 56, 13704-13714. [CrossRef]

17. Hörold, S. Phosphorus-based and Intumescent Flame Retardants. In Polymer Green Flame Retardants; Elsevier: Amsterdam, The Netherlands, 2014; pp. 221-254.

18. Kleiner, H.-J.; Budzinsky, W.; Kirsch, G. Low-Flammability Polyamide Molding Materials. US5773556A, 30 June 1998. Available online: https:/ / patents.google.com/patent/US5773556A (accessed on 2 August 2018).

19. Braun, U.; Bahr, H.; Schartel, B. Fire retardancy effect of aluminium phosphinate and melamine polyphosphate in glass fibre reinforced polyamide 6. E-Polymers 2010, 10. [CrossRef]

20. Jenewein, E.; Kleiner, H.-J. Synergistic Flame Protection Agent Combination for Thermoplastic Polymers. EP0892829B1, 02 April 1997. Available online: https:/ / patents.google.com/patents/EP0892829B1 (accessed on 12 August 2018).

21. Braun, U.; Schartel, B.; Fichera, M.A.; Jäger, C. Flame retardancy mechanisms of aluminium phosphinate in combination with melamine polyphosphate and zinc borate in glass-fibre reinforced polyamide 6,6. Polym. Degrad. Stab. 2007, 92, 1528-1545. [CrossRef]

22. Didane, N.; Giraud, S.; Devaux, E.; Lemort, G. Development of fire resistant PET fibrous structures based on phosphinate-POSS blends. Polym. Degrad. Stab. 2012, 97, 879-885. [CrossRef]

23. Mandlekar, N.; Malucelli, G.; Cayla, A.; Rault, F.; Giraud, S.; Salaün, F.; Guan, J. Fire retardant action of zinc phosphinate and polyamide 11 blend containing lignin as a carbon source. Polym. Degrad. Stab. 2018, 153, 63-74. [CrossRef]

24. Troitzsch, J. Plastics Flammability Handbook: Principles, Regulations, Testing, and Approval; Hanser: Munich, Germany, 2004.

25. ISO 5660. Fire Test, Reaction to Fire, Rate of Heat Release (Cone Calorimeter Method); International Organization for Standardization: Geneva, Switzerland, 2002.

26. Song, P.; Cao, Z.; Fu, S.; Fang, Z.; Wu, Q.; Ye, J. Thermal degradation and flame retardancy properties of ABS/lignin: Effects of lignin content and reactive compatibilization. Thermochim. Acta 2011, 518, 59-65. [CrossRef]

27. Sicken, M.; Schlosser, E.; Wanzke, W.; Burghardt, D. Fusible Zinc Phosphinate. US20040176506A1, 9 September 2004.

28. Battegazzore, D.; Alongi, J.; Fontaine, G.; Frache, A.; Bourbigot, S.; Malucelli, G. Bulk vs. surface flame retardancy of fully bio-based polyamide 10,10. RSC Adv. 2015, 5, 39424-39432. [CrossRef]

29. Vannier, A.; Duquesne, S.; Bourbigot, S.; Alongi, J.; Camino, G.; Delobel, R. Investigation of the thermal degradation of PET, zinc phosphinate, OMPOSS and their blends-Identification of the formed species. Thermochim. Acta 2009, 495, 155-166. [CrossRef]

30. Sut, A.; Greiser, S.; Jäger, C.; Schartel, B. Aluminium diethylphosphinate versus ammonium polyphosphate: A comprehensive comparison of the chemical interactions during pyrolysis in flame-retarded polyolefine/poly(phenylene oxide). Thermochim. Acta 2016, 640, 74-84. [CrossRef]

31. Hosoya, T.; Kawamoto, H.; Saka, S. Role of methoxyl group in char formation from lignin-related compounds. J. Anal. Appl. Pyrolysis 2009, 84, 79-83. [CrossRef]

32. Braun, U.; Bahr, H.; Sturm, H.; Schartel, B. Flame retardancy mechanisms of metal phosphinates in combination with melamine cyanurate in glass-fiber reinforced poly (1,4-butylene terephthalate): The influence of metal cation. Polym. Adv. Technol. 2008, 19, 680-692. [CrossRef]

33. Jakab, E.; Till, F.; Székely, T.; Faix, O. Thermogravimetry/mass spectrometry of various lignosulfonates as well as of a kraft and acetosolv lignin. Holzforschung 1991, 45, 355-360. [CrossRef]

34. Didane, N.; Giraud, S.; Devaux, E. Fire performances comparison of back coating and melt spinning approaches for PET covering textiles. Polym. Degrad. Stab. 2012, 97, 1083-1089. [CrossRef]

35. Braun, U.; Schartel, B. Flame retardant mechanisms of red phosphorus and magnesium hydroxide in high impact polystyrene. Macromol. Chem. Phys. 2004, 205, 2185-2196. [CrossRef]

36. Lewin, M.; Weil, E. Mechanisms and Modes of Action in Flame Retardancy of Polymers; Woodhead Publishing Ltd.: Cambridge, UK, 2001; pp. 31-68.

37. Mouritz, A.P.; Mathys, Z.; Gibson, A.G. Heat release of polymer composites in fire. Compos. Part A Appl. Sci. Manuf. 2006, 37, 1040-1054. [CrossRef] 
38. Schartel, B.; Hull, T.R. Development of fire-retarded materials-Interpretation of cone calorimeter data. Fire Mater. 2007, 31, 327-354. [CrossRef]

39. Ferry, L.; Dorez, G.; Taguet, A.; Otazaghine, B.; Lopez-Cuesta, J.M. Chemical modification of lignin by phosphorus molecules to improve the fire behavior of polybutylene succinate. Polym. Degrad. Stab. 2015, 113, 135-143. [CrossRef]

40. Chen, J.; Liu, S.; Zhao, J. Synthesis, application and flame retardancy mechanism of a novel flame retardant containing silicon and caged bicyclic phosphate for polyamide 6. Polym. Degrad. Stab. 2011, 96, 1508-1515. [CrossRef]

41. Braun, U.; Schartel, B. Effect of red phosphorus and melamine polyphosphate on the fire behavior of HIPS. J. Fire Sci. 2005, 23, 5-30. [CrossRef]

42. Huang, W.; He, W.; Long, L.; Yan, W.; He, M.; Qin, S.; Yu, J. Highly efficient flame-retardant glassfiber-reinforced polyamide 6T system based on a novel DOPO-based derivative: Flame retardancy, thermal decomposition, and pyrolysis behaviour. Polym. Degrad. Stab. 2018, 148, 26-41. [CrossRef]

43. Zhan, Z.; Xu, M.; Li, B. Synergistic effects of sepiolite on the fl ame retardant properties and thermal degradation behaviors of polyamide 66/aluminum diethylphosphinate composites. Polym. Degrad. Stab. 2015, 117, 66-74. [CrossRef]

(C) 2019 by the authors. Licensee MDPI, Basel, Switzerland. This article is an open access article distributed under the terms and conditions of the Creative Commons Attribution (CC BY) license (http://creativecommons.org/licenses/by/4.0/). 